Pacific Northwest National Laboratory

Operated by Batielle for the U.S. Deparment of Energy

\section{Airborne Effluent Monitoring System Certification for New Canister Storage Building Ventilation Exhaust Stack}

J. A. Glissmeyer
A. D. Maughan

March 1999

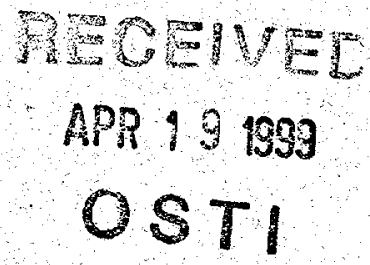

Prepared for the U.S. Department of Energy under Contract DE-AC06-76RLO 1830 


\title{
DISCLAIMER
}

This report was prepared as an account of work sponsored by an agency of the United States Government. Neither the United States Government nor any agency thereof, nor Battelle Memorial Institute, nor any of their employees, makes any warranty, express or implied, or assumes any legal liability or responsibility for the accuracy, completeness, or usefulness of any information, apparatus, product, or process disclosed, or represents that its use would not infringe privately owned rights. Reference herein to any specific commercial product, process, or service by trade name, trademark, manufacturer, or otherwise does not necessarily constitute or imply its endorsement, recommendation, or favoring by the United States Government or any agency thereof, or Battelle Memorial Institute. The views and opinions of authors expressed herein do not necessarily state or reflect those of the United States Government or any agency thereof.

\author{
PACIFIC NORTHWEST NATIONAL LABORATORY \\ operated by \\ BATTELLE \\ for the
}
UNITED STATES DEPARTMENT OF ENERGY
under Contract DE-ACO6-76RLO 1830

\author{
Printed in the United States of America \\ Available to DOE and DOE contractors from the \\ Office of Scientific and Technical Information, P.O. Box 62, Oak Ridge, TN 37831; \\ prices available from $(615) 576-8401$.
}

Available to the public from the National Technical Information Service, U.S. Department of Commerce, 5285 Port Royal Rd., Springfield, VA 22161 


\title{
Airborne Effluent Monitoring System Certification for New \\ Canister Storage Building Ventilation Exhaust Stack
}

\author{
J. A. Glissmeyer
}

A. D. Maughan

March 1999

Prepared for

the U.S. Department of Energy

under Contract DE-AC06-76RLO 1830

Pacific Northwest National Laboratory

Richland, Washington 99352 


\section{Summary}

Pacific Northwest National Laboratory conducted three of the six tests needed to verify that the effluent monitoring system for the new Canister Storage Building ventilation exhaust stack meets applicable regulatory performance criteria for air sampling systems at nuclear facilities. These performance criteria address both the suitability of the location for the air-sampling probe and the transport of the sample to the collection devices. The criteria covering the location for the air-sampling probe ensure that the contaminants in the stack are well mixed with the airflow at the probe location such that the extracted sample represents the whole. The sample-transport criteria ensure that the sampled contaminants are quantitatively delivered to the collection device. The specific performance criteria are described in detail in this report. The tests reported here cover the contaminant tracer uniformity and particle delivery performance criteria. These criteria were successfully met.

The other three tests were conducted by the start-up staff of Duke Engineering and Services Hanford Inc. (DESH) and reported elsewhere.

The Canister Storage Building is located in the 200 East Area of the U.S. Department of Energy's Hanford Site near Richland, Washington. The new air-exhaust system was built under the W379 Project. The air sampling system features a probe with a single shrouded sampling nozzle, a sample delivery line, and a filter holder to collect the sample. 
. 


\section{Acknowledgments}

This work was supported by the U.S. Department of Energy under Contract DE-AC06-76RLO 1830, with project funding from Duke Engineering and Services Hanford, Inc (DESH). The authors wish to acknowledge the staff of DESH for their assistance in conducting the tests. 
. 


\section{Contents}

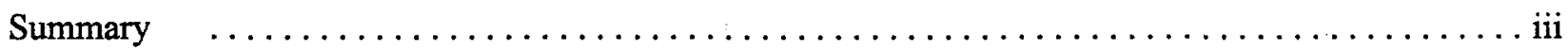

Acknowledgments $\ldots \ldots \ldots \ldots \ldots \ldots \ldots \ldots \ldots \ldots \ldots \ldots \ldots \ldots \ldots \ldots \ldots \ldots \ldots \ldots \ldots \ldots \ldots$

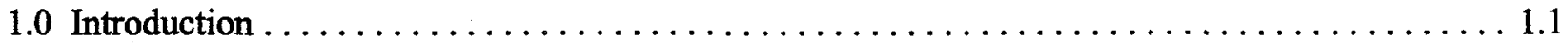

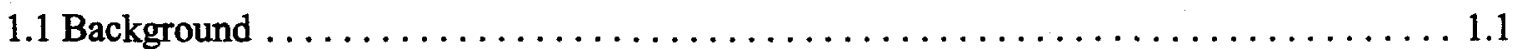

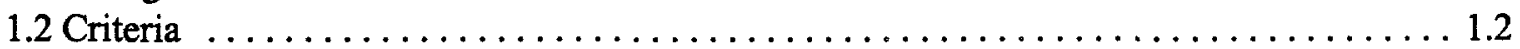

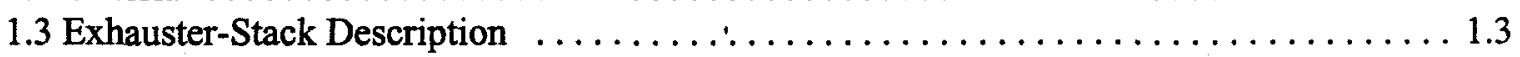

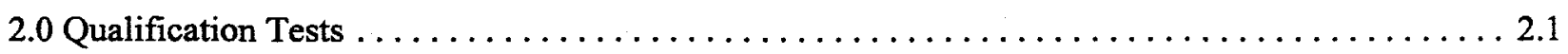

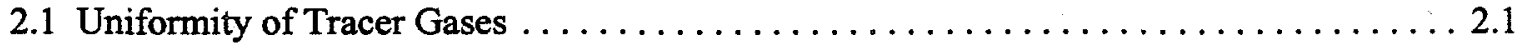

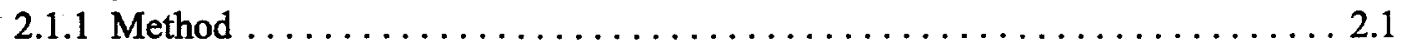

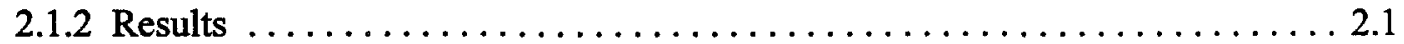

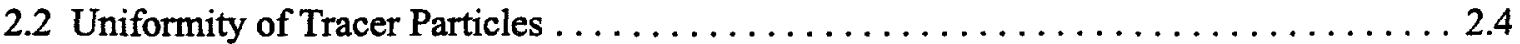

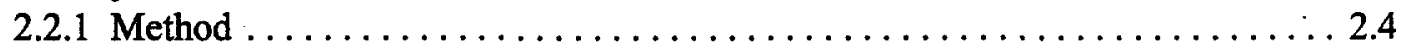

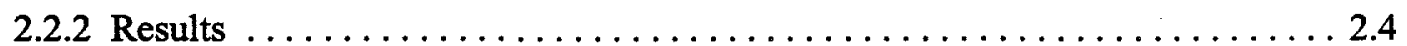

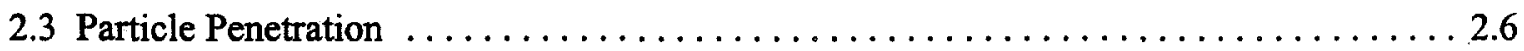

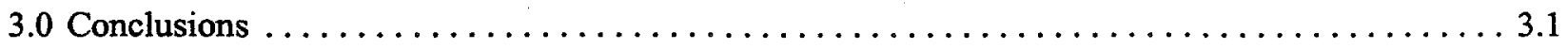

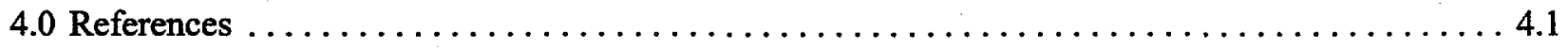

Appendix A - Test to Determine Uniformity of Tracer Gases $\ldots \ldots \ldots \ldots \ldots \ldots \ldots \ldots \ldots$.1

Appendix B - Test to Determine Uniformity of Tracer Particles $\ldots \ldots \ldots \ldots \ldots \ldots \ldots \ldots \ldots$

Appendix C - Particle Penetration Calculation $\ldots \ldots \ldots \ldots \ldots \ldots \ldots \ldots \ldots \ldots \ldots \ldots \ldots \ldots \ldots$ 


\section{Figures}

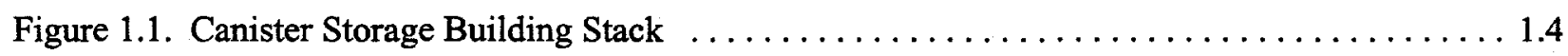

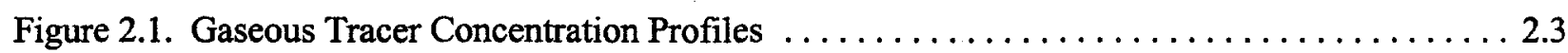

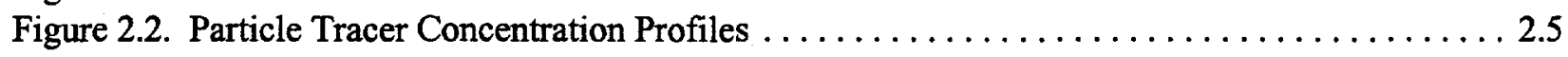

\section{Tables}

Table 2.1. Tracer Gas Mixing over the Center Two-Thirds of the Stack $\ldots \ldots \ldots \ldots \ldots \ldots \ldots 2.2$

Table 2.2. Tracer Particle Mixing over the Center Two-Thirds of the Stack $\ldots \ldots \ldots \ldots \ldots \ldots .5$ 


\subsection{Introduction}

The new Canister Storage Building, located in the 200 East Area of the U.S. Department of Energy's (DOE's) Hanford Site, includes a ventilation exhaust stack with an air monitoring system. This air monitoring system must be shown to meet applicable standards and regulatory criteria. Some criteria ensure that the contaminants in the stack are well mixed with the airflow at the probe location so that the extracted sample represents the whole. Other criteria address the transport of the sample to the collection device. The specific performance criteria are described in this report.

Compliance with most of the criteria is demonstrated by testing. Some of the testing was conducted by the start-up staff of Duke Engineering and Services Hanford Inc. (DESH) and reported elsewhere. This report covers the work performed by Pacific Northwest National Laboratory (PNNL). The detailed test procedures and data sheets are included in the appendices.

\subsection{Background}

On December 15, 1989, 40 CFR 61, Subpart H, "National Emission Standards for Emissions of Radionuclides Other than Radon from Department of Energy Facilities," came into effect. This regulation governs portions of the design and implementation of facility effluent air sampling. Further, 40 CFR $61 \mathrm{H}$ requires the use of isokinetic ${ }^{\mathrm{a}}$ sampling nozzles as described in American National Standards Institute (ANSI) N13.1-1969 (ANSI 1982). More recent research (Rodgers et al. 1996; Glissmeyer and Ligotke 1995) indicates poor performance for isokinetic nozzles relative to that of the shrouded nozzle. The U.S. Environmental Protection Agency (EPA) has approved a DOE alternativemethod petition that allows the use of a sampling probe with a single shrouded nozzle in applications that previously required a probe with several isokinetic nozzles ${ }^{b}$. This single-point sample-extraction approach is applicable where the potential contaminants in the effluent are of a uniform concentration at the sampling location. This was a significant departure from the ANSI N13.1-1969 approach in that now

(a) Air samples are extracted from the bulk airflow through a probe having a round orifice that is aerodynamically designed. The opening is generally pointed directly into the airflow. The term isokinetic means that the air velocity through the probe orifice matches that of the approaching airstream. This theoretically ensures that the sample airstream has the same concentration of particles of all sizes per unit air volume as the bulk airstream. If the probe-orifice air velocity is lower than that of the bulk airstream, it is operating "subisokinetically." In this case, particles with significant inertia will be present in the sample airstream in a concentration greater than in the bulk airstream.

(b) U. S. Environmental Protection Agency. 1994. Letter from Mary Nichols to Raymond Pelletier (11/21/94). Washington, D.C. 
the sampling system must meet specific performance criteria. These performance criteria are incorporated in ANSI N13.1-1999 to be published in May of 1999.a

\subsection{Criteria}

The qualification criteria for location of the sampling probe are as follows:

1. Angular Flow - Sampling nozzles are usually aligned with the axis of the stack. If the air travels up the stack in cyclonic fashion, the air velocity vector approaching the nozzle could be misaligned with the sampling nozzles enough to impair the extraction of particles. Consequently, the flow angle is measured in the stack at the elevation of the sampling nozzle. The average air-velocity angle must not deviate from the axis of the sampling nozzle by more than $20^{\circ}$.

2. Uniform Air Velocity - It is important that the gas momentum across the stack cross section where the sample is extracted be uniform. Consequently, the velocity is measured at several points in the stack at the elevation of the sampling nozzle. The uniformity is expressed as the variability of the measurements about the mean. This is expressed using the relative coefficient of variance (COV), which is the standard deviation divided by the mean and expressed as a percentage. The lower the COV value, the more uniform the velocity. The acceptance criterion is that the COV of the air velocity must be $\leq \mathbf{2 0 \%}$ across the center two-thirds of the area of the stack.

3. Uniform Concentration of Tracer Gases - A uniform contaminant concentration in the sampling plane enables the extraction of samples that represent the average concentration. This is first tested using a tracer gas to represent gaseous effluents. The fan is a good mixer, so injecting the tracer downstream of the fan provides worst-case results. The acceptance criteria are that 1 ) the COV of the measured tracer gas concentration is $\leq 20 \%$ across the center two-thirds of the sampling plane and 2) at no point in the sampling plane does the concentration vary from the mean by $>30 \%$.

4. Uniform Concentration of Tracer Particles - Uniformity in contaminant concentration at the sampling elevation is further demonstrated using tracer particles large enough to exhibit inertial effects. Particles of $10-\mu \mathrm{m}$ aerodynamic diameter ${ }^{b}(\mathrm{AD})$ are used by default unless it is known that larger particles are present in the airstream. The acceptance criterion is that the COV of particle concentration is $\leq 20 \%$ across the center two-thirds of the sampling plane.

${ }^{2}$ Health Physics Society/American National Standards Institute (ANSI). Draft. "HPS/ANSI N13.11999 Sampling and monitoring releases of airborne radioactive substances form the stacks and ducts of nuclear facilities." American National Standards Institute, New York.

'The aerodynamic diameter of a particle of arbitrary shape and density is the diameter of a spherical water droplet that has the same sedimentation velocity in quiescent air as the arbitrary particle. Particles with the same aerodynamic diameter will exhibit the same aerodynamic behavior even if they vary in shape and density. 
Additional criteria would apply if scale-model testing had been conducted. In this case, the actual stack was used in testing.

Finally, the standard requires a demonstration to show that the extracted sample reaches the sample filter. The sample transport system is required to deliver more than $50 \%$ of $10-\mu \mathrm{m}-\mathrm{AD}$ particles from the stack to the sample collector. Also, the sampling nozzle must have the following characteristics:

- transmission ratio at $10 \mu \mathrm{m}$ is 0.8 to 1.3

- nozzle aspiration ratio at $10 \mu \mathrm{m}$ is 0.8 to 1.5 .

The nozzle characteristics are inherent in the design and were verified in wind-tunnel tests (McFarland et al. 1989; Glissmeyer and Ligotke 1995) and in the manufacturer's submittals. The overall particle transport is required to be verified experimentally or with the DEPOSITION code (Riehl et al. 1996).

PNNL performed the tests and calculations to verify compliance with the tracer-uniformity and particle-delivery criteria. Compliance with the other criteria is covered in DESH reports.

\subsection{Exhauster-Stack Description}

All tests were done on the actual stack at the Canister Storage Building. The stack is depicted in Figure 1.1. The stack has an internal diameter of 27.19 inches and is about 75 -feet tall. It is equipped with two fans, used one at a time. The range of operating airflow in the stack was narrow, 9050 to $9300 \mathrm{cfm}$, as determined by DESH instrumentation.

The tip of the sampling nozzle is about 219.25 inches (about 8.0 stack diameters) above the top of the duct entering the stack at a $45^{\circ}$ upward angle. Test ports were located in the stack a few inches below the sampling nozzle. Tracer injection ports were located between the fan and the stack. Other test ports were installed higher on the stack to use in testing the airflow measurement system. 


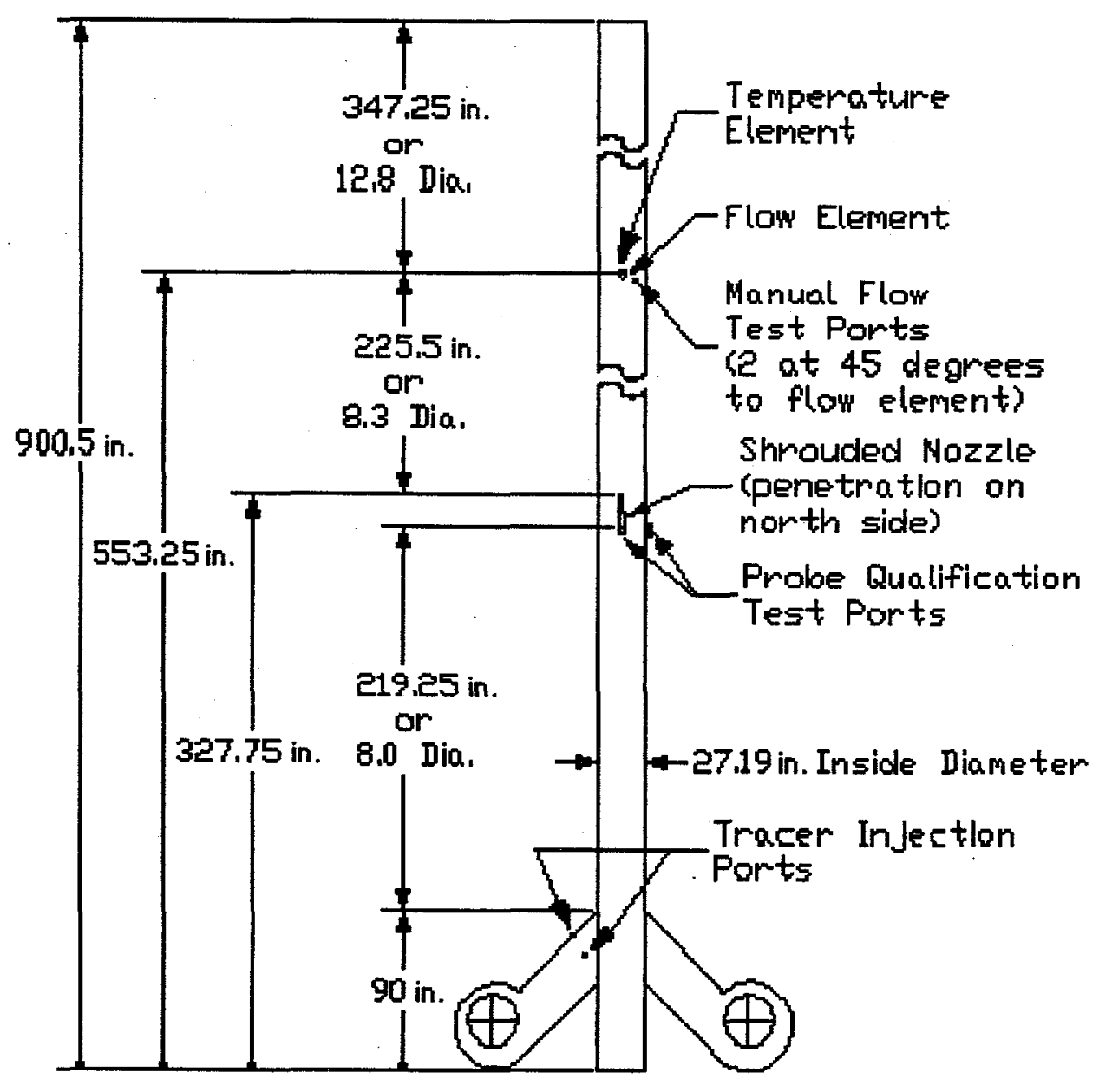

Figure 1.1. Canister Storage Building Stack 


\subsection{Qualification Tests}

The qualification test methods and results are described below. PNNL conducted the tests and calculations to determine compliance with the performance criteria covering gaseous-tracer uniformity, particle-tracer uniformity, and particle penetration. DESH conducted and documented the tests to determine compliance with performance criteria covering angular flow and velocity uniformity.

\subsection{Uniformity of Tracer Gases}

\subsubsection{Method}

A uniform contaminant concentration at the sampling plane enables the extraction of samples representative of the average concentration. The gaseous contaminant concentration uniformity was demonstrated using sulfur hexafluoride as a tracer gas. For each test, the tracer was injected into the airstream at one of five points in the cross section of the rectangular duct between the fan and the stack (at the centerline and near each corner), as shown in Figure 1.1. The corner injection points were about 0.71 inch (approximately $3 \%$ of a hydraulic diameter) inward from each corner. The centerline injection test was repeated twice.

The tracer concentration was measured over agrid points in a cross section of the stack at the elevation of the sampling nozzle. The measurement grid of 25 points, in an " $x$ "-shaped pattern, was laid out in accordance with the EPA procedure 40 CFR 60, Appendix A, Method 1. The tracer concentration was measured using a Bruel and Kjaer (Naerum, Denmark) Model 1302 gas analyzer calibrated for the tracer gas. The procedure is detailed in Appendix A. The COV (the standard deviation divided by the mean) of the average concentration readings at each point of the 25 points is calculated and the result compared to the acceptance criterion for uniformity.

\subsubsection{Results}

Table 2.1 summarizes the results, and the data sheets for the individual test runs are included in Appendix A. The acceptance criteria are that 1) the COV of the tracer gas concentration must be $\leq 20 \%$ across the center two-thirds of the sampling plane and 2) at none of the measurement points does the average concentration differ from the mean concentration by $>30 \%$. 
Table 2.1. Tracer Gas Mixing over the Center Two-Thirds of the Stack

\begin{tabular}{||l|c|}
\hline Injection point & $\begin{array}{c}\text { \% COV (Maximum \% } \\
\text { Deviation from Mean) }\end{array}$ \\
\hline \hline Center & $7.9,7.3,6.9(23 \%)$ \\
\hline Top left & $2.9(6 \%)$ \\
\hline Top right & $6.4(17 \%)$ \\
\hline Bottom left & $1.9(6 \%)$ \\
\hline Bottom right & $6.3(13 \%)$ \\
\hline
\end{tabular}

The worst case result was when the tracer was injected at the center of the fan outlet duct. The COV results ranged from $1.9 \%$ to $7.9 \%$ for the center $2 / 3$ area of the stack, and the largest deviation of any single-point concentration from the mean concentration was $23 \%$. Therefore, the acceptance criteria were met in all cases.

Figure 2.1 is a comparison of tracer concentrations profiles for each injection position. The vertical axis is exaggerated to emphasize the differences. The data were normalized so the plotted centerpoint value was equal for both traverse directions. 
Center injection, $\operatorname{COV}=\mathbf{7 . 9 \%}$

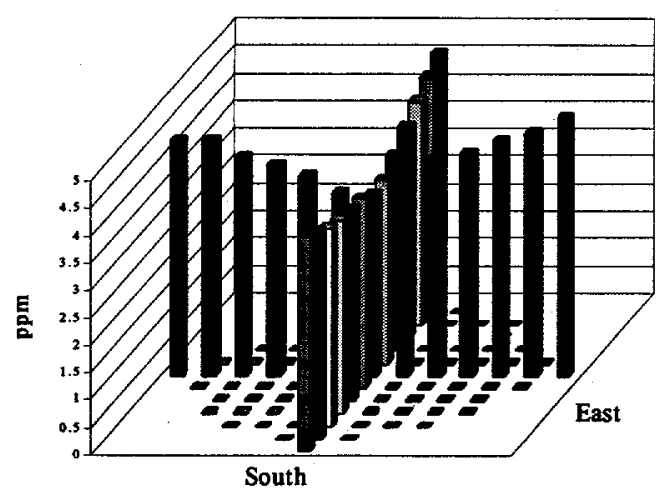

Upper left injection, $\operatorname{COV}=2.9 \%$
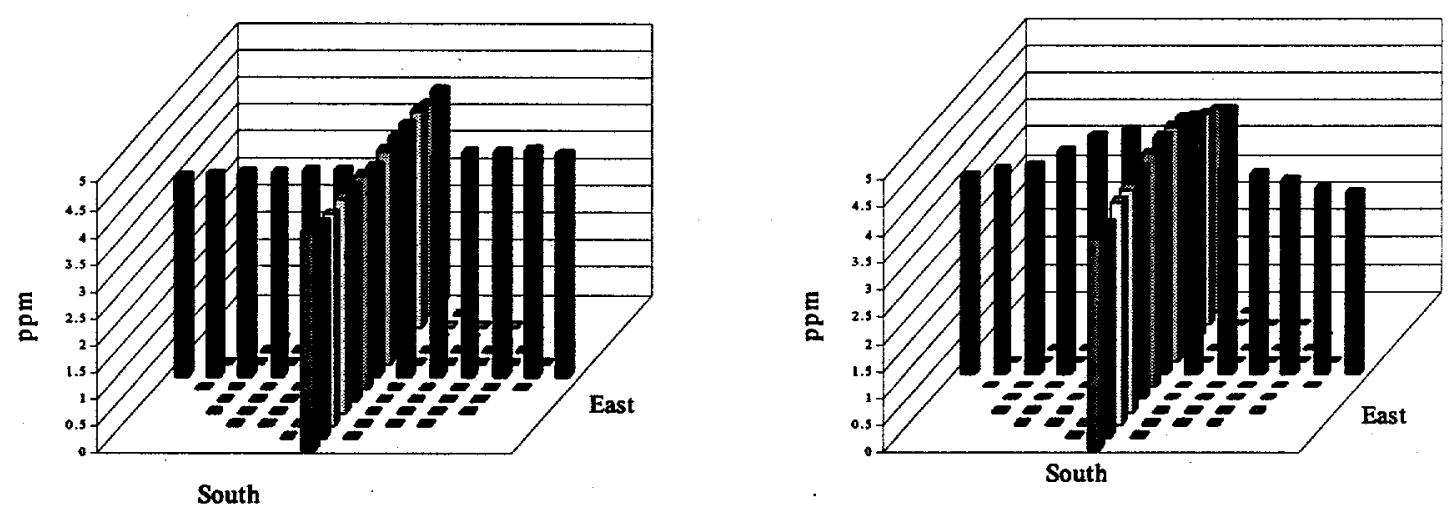

Lower left injection, $\operatorname{COV}=1.9 \%$

Lower right injection, $\mathrm{COV}=6.6 \%$
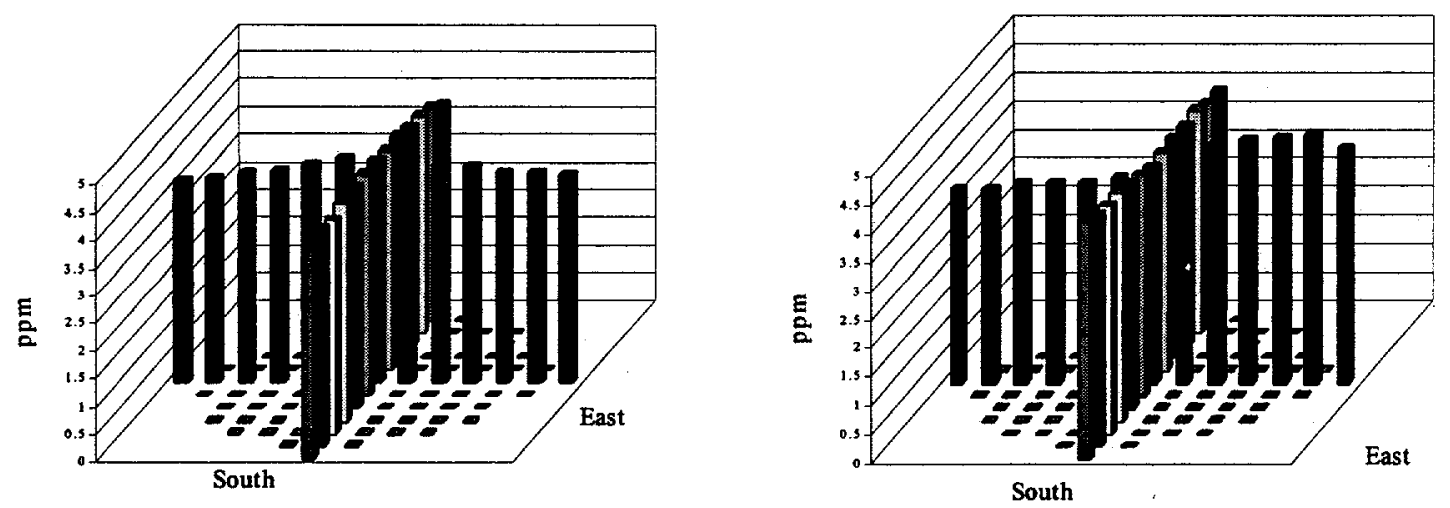

Figure 2.1. Gaseous-Tracer Concentration Profiles 


\subsection{Uniformity of Tracer Particles}

\subsubsection{Method}

The test for uniformity of tracer particles is similar to the test for uniformity of tracer gases. The general approach is to inject particles of a range of sizes, including the size of interest, into the test stack just downstream of the fan. The concentration of the particles of the size of interest is then measured at several points in the cross section of the sampling plane using an optical particle counter (OPC, Met-One Model A2408, Grants Pass, Oregon). The particles were made by spraying vacuum-pump oil through a nozzle.

A simple probe was used to extract the sample and transport it to the OPC. The OPC and its probe were moved from point to point in random order, first in one traverse direction and then the other. Because the generation rate for tracer particles may vary with time, a second OPC was used to observe the particle concentration from a fixed point in the stack. The data from the mobile OPC can then be adjusted if a temporal trend is observed with the fixed OPC.

The tracer particles only needed to be injected along the centerline of the rectangular duct between the fan and stack, as shown in Figure 1.1.

The OPCs sort the number of particles into six size channels. Each concentration reading was the count of particles collected in the 9- to $11-\mu \mathrm{m}$ channel. The particle mixing is acceptable if the COV of the tracer particles of $10-\mu \mathrm{m}$ aerodynamic diameter $(\mathrm{AD})$ is $\leq 20 \%$ across the center two-thirds of the sampling plane. The detailed procedure is included in Appendix B.

\subsubsection{Results}

The particle-concentration uniformity was measured at extremes of the flowrate. The data sheets for each run are included in Appendix B, and Table 2.2 summarizes the test results. The row labeled "raw data" shows results without any normalization with time. The results after normalization are also shown. The normalization method adjusted all of the concentration readings by the same amount so that the centerpoint readings taken via the two traverse directions equaled their average. The effect of normalization is more pronounced in cases where there was a shift in concentration with time. 
Table 2.2. Tracer Particle Mixing over the Center Two-Thirds of the Stack

\begin{tabular}{|l|c|}
\hline & $\begin{array}{c}\% \text { Coefficient of } \\
\text { Variation at } \\
\text { Flowrate Given }\end{array}$ \\
\hline \hline Raw data & $17.0,19.2$ \\
\hline Normalized & $15.7,18.2$ \\
\hline
\end{tabular}

Figure 2.2 shows the particle-concentration profiles for both runs. Both runs were conducted for the same set of operating conditions and both showed the highest concentration on the west side of the stack, which is the same side as the operational fan. It is assumed that the high concentration will switch to the east side when the other fan is operated instead. The sampling probe runs along the North/South direction, and the nozzle is located in the northern half. It is expected that the concentration at this location is not greatly affected by the operation of either fan.
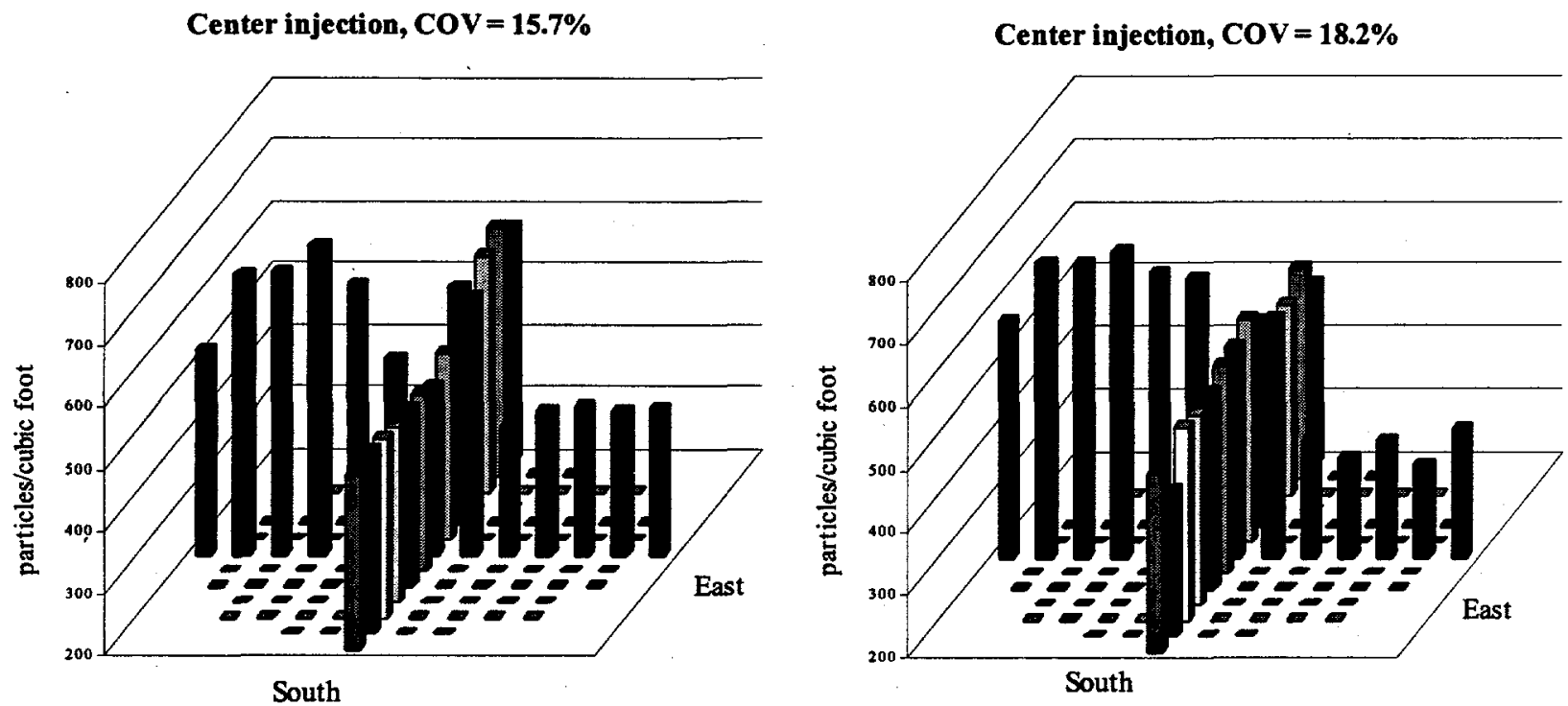

Figure 2.2. Particle-Tracer Concentration Profiles

The fact that the COV is higher for the particle tracer than for the gaseous tracer indicates that the particles mix slower, as expected, because of their inertial and drag properties. The gas mixes very well with the air, so the concentration is quite uniform. This underscores the value of the separate tests because the results of one test do not predict those of the others. 


\subsection{Particle Penetration}

The DEPOSITION code was used to model the penetration of $10-\mu \mathrm{m} A D$ particles through the entire sampling system from the probe nozzle to the filter holder. The overall results were penetrations of $91 \%$ for the mean stack air flow of $9300 \mathrm{cfm}$. This exceeds the minimum penetration of $50 \%$. The output details of the code runs are shown in Appendix C. 


\subsection{Conclusions}

The tests conducted on the Canister Storage Building stack demonstrated that the locations for the air-sampling probe meet the tracer-mixing and particle-penetration performance criteria for air sampling systems at nuclear facilities. The conclusions are summarized for each performance criterion. The individual criteria were explained earlier in the report.

The performance criteria and conclusions are as follows:

1. Uniform Concentration of Tracer Gases - The acceptance criteria were that a) the COV of the measured tracer gas concentration must be $\leq 20 \%$ across the center two-thirds of the sampling plane and $b$ ) at no point in the sampling nozzle elevation does the concentration vary from the mean by $>30 \%$. The results met the criterion with the COV ranging from $1.9 \%$ to $7.9 \%$,depending on the injection point used. The largest deviation of any single point concentration from the mean concentration in any run was $23 \%$.

2. Uniform Concentration of Tracer Particles - The acceptance criterion was that the COV of particle concentration must be $\leq 20 \%$ across the center two-thirds of the sampling plane. The results normalized for concentration fluctuations with time met the criterion with the COV ranging from $15.7 \%$ to $18.2 \%$, depending on the flowrate used on the full-scale model.

3. Sample Transport - The acceptance criterion was that the sample-transport system must deliver more than $50 \%$ of $10-\mu \mathrm{m}-\mathrm{AD}$ particles from the stack to the sample collector. The particle penetration result from the DEPOSITION code was $91 \%$ for the stack flowrate of $9300 \mathrm{cfm}$.

4. Sampling Nozzles - The acceptance criteria for nozzles were that the transmission be in the 0.8 to 1.3 range and that the aspiration ratio be in the 0.8 to 1.5 range for $10-\mu \mathrm{m}-\mathrm{AD}$ particles. The nozzle characteristics are inherent in the design and were verified in wind tunnel tests (McFarland et al. 1989; Glissmeyer and Ligotke 1995) and in the manufacturer's submittals. 


\subsection{References}

40 CFR 60, Appendix A, Method 1, U.S. Environmental Protection Agency, "Method 1 - Sample and Velocity Traverses for Stationary Sources.” Code of Federal Regulations.

40 CFR 61, Subpart H, U.S. Environmental Protection Agency, "National Emission Standards for Emissions of Radionuclides Other than Radon from Department of Energy Facilities." Code of Federal Regulations.

American National Standards Institute (ANSI). 1982 (Reaffirmed). "ANSI N13.1-1969 Guide to Sampling Airborne Radioactive Materials in Nuclear Facilities." American National Standards Institute, New York.

Glissmeyer, J. A., and M. W. Ligotke. 1995. Generic Air Sampler Probe Tests. PNL-10816, Pacific Northwest Laboratory, Richland, Washington.

McFarland, A. R., C. A. Ortiz, M. E. Moore, R. E. DeOtte, Jr., and A. Somasundaram. 1989. "A Shrouded Aerosol Sampling Probe." Environ. Sci. Technol. 23:1487-1492.

Riehl, J. R., V. R. Dileep, N. K. Anand, and A. R. McFarland. 1996. DEPOSITION 4.0: An Illustrated User's Guide. Aerosol Technology Laboratory Report 8838/7/96, Department of Mechanical Engineering, Texas A\&M University, College Station, Texas.

Rodgers, J. C., C. I. Fairchild, G. O. Wood, C. A. Ortiz, A. Muyshondt, and A. R. McFarland. 1996. "Single Point Aerosol Sampling: Evaluation of Mixing and Probe Performance in a Nuclear Stack." Health Physics 70:25-35. 


\section{Appendix A}

\section{Test to Determine Uniformity of Tracer Gases}




\begin{tabular}{|c|c|c|c|}
\hline \multicolumn{4}{|c|}{ \{PRIVATE \}PNNL Operating Procedure } \\
\hline $\begin{array}{l}\text { Title: Test to Determine } \\
\text { Uniformity of a Tracer } \\
\text { Gas at a Sampler } \\
\text { Probe }\{\text { PRIVATE }\}\end{array}$ & $\begin{array}{l}\text { Org. Code: } \\
\text { Procedure No.: } \\
\text { Rev. No.: }\end{array}$ & \multicolumn{2}{|c|}{$\begin{array}{l}\text { D9T99 } \\
\text { EMS-JAG-01 } \\
0\end{array}$} \\
\hline Work Location: General & Effective Date: & \multicolumn{2}{|c|}{ November 10,1998} \\
\hline Author: John A. Glissmeyer & \multicolumn{3}{|c|}{ Supersedes Date: } \\
\hline $\begin{array}{l}\text { Identified Hazards: } \\
\text { Radiological } \\
\text { Hazardous Materials } \\
\text { — Physical Hazards } \\
\text { Hazardous Environment } \\
\text { Other: }\end{array}$ & \multicolumn{3}{|c|}{$\begin{array}{l}\text { Identified Use Category: } \\
\text { Mandatory Use } \\
\text { Continuous Use } \\
\text { Reference Use } \\
\text { Information Use }\end{array}$} \\
\hline \multicolumn{4}{|c|}{ Are One-Time Modifications Allowed? $\quad$ Yes $\quad$ No } \\
\hline Person Signing & \multicolumn{2}{|c|}{ Signature } & Date \\
\hline $\begin{array}{l}\text { Technical review: } \\
\text { James L. Huckaby }\end{array}$ & & & \\
\hline $\begin{array}{l}\text { Project Manager: } \\
\text { John Glissmeyer }\end{array}$ & & & \\
\hline $\begin{array}{l}\text { Line Manager: } \\
\text { James Droppo }\end{array}$ & & & \\
\hline Concurrence: & & & \\
\hline $\begin{array}{l}\text { Quality Engineer: } \\
\text { Thomas G. Walker }\end{array}$ & & & \\
\hline
\end{tabular}




\begin{tabular}{|l|ll|}
\hline PNNL Operating Procedure & $\begin{array}{l}\text { Rev. No. } 0 \\
\text { Org. Code: D9T99 }\end{array}$ & $\begin{array}{l}\text { Page 2 of 16 } \\
\text { Procedure No.: EMS-JAG-01 }\end{array}$ \\
\hline \multicolumn{2}{|c|}{ Title: Test to Determine Uniformity of a Tracer Gas at a Sampler Probe } \\
\hline
\end{tabular}

\subsection{Purpose}

The performance of new stack sampling systems must be shown to satisfy the requirements of 40 CFR 61, Subpart H, "National Emission standards for Emissions of Radionuclides Other than Radon from Department of Energy Facilities." This regulation governs portions of the design and implementation of effluent air sampling. The stack sampler performance is adequately characterized when potential contaminants in the effluent are of a uniform concentration at the sampling location (plane) and line losses are within acceptable limits. This procedure determines whether the concentration of gaseous contaminants is uniformly distributed in the area of the sampling probe. Other procedures address flow angle, uniformity of gas velocity, and uniformity of particulate contaminants. A contaminant concentration that is uniform at the sampling plane enables the extraction of samples that represent the true emission concentration.

The uniformity is expressed as the variability of the measurements about the mean. This is expressed using the relative coefficient of variance (COV), which is the standard deviation divided by the mean and expressed as a percentage. The lower the COV value, the more uniform the velocity. The acceptance criterion is that the COV of the air velocity be $\leq 20 \%$ across the center two-thirds of the area of the stack. This allows for slightly more than a 2:1 variability in velocity measurements in the stack cross section.

\subsection{Applicability}

This procedure can be used in the field or on modeled stacks to determine whether air-sampling probes can collect representative samples under normal operations. The tests are applicable to effluent stacks or ducts within the following constraints:

- The tracer gas tests are generally limited to stacks with flowrates greater than 50 cubic feet per minute range. The upper bound of flowrate is determined by the sensitivity of the gas analyzer, the background reading for the tracer gas, and the availability of the tracer.

- Environmental constraints -- the gas analyzer will require the use of a controlled temperature environment to maintain the equipment above 55 degrees Fahrenheit.

\subsection{Prerequisites and Conditions}

Conditions and concerns that must be satisfied prior to sampling are listed below:

- Safety glasses, hard toed or substantial shoes are required to in the work areas.

- Scaffold user training is required to access the sampling ports of the stack.

- Alcohol will be used for equipment cleanup. A flammable equipment storage cabinet is required to hold chemicals.

- Pressurized cylinders of gas will be used to supply the tracer gas for tests. Knowledge of the use and operation of gas delivery system and the ability to detect any concentration trend build-ups of 


\begin{tabular}{|l|ll|}
\hline PNNL Operating Procedure & $\begin{array}{l}\text { Rev. No. } 0 \\
\text { Org. Code: D9T99 }\end{array}$ & $\begin{array}{l}\text { Page 3 of 16 } \\
\text { Procedure No.: EMS-JAG-01 }\end{array}$ \\
\hline \multicolumn{2}{|c|}{ Title: Test to Determine Uniformity of a Tracer Gas at a Sampler Probe } \\
\hline
\end{tabular}

the gas is essential to prevent exceeding ACGIH levels listed below.

- Knowledge for the setup, use of, and operation of flowmeters, gas analyzers, and computers is essential.

- The job-hazards analysis must be followed.

\subsection{Precautions and Limitations}

Caution: The American Conference of Governmental Industrial Hygienists (ACGIH) 8-hour timeweighted average limit for human exposure to sulfur hexafluoride gas is $1000 \mathrm{ppm}\left(6,000 \mathrm{mg} / \mathrm{m}^{3}\right)$. It is colorless and odorless.

During tests of stacks with high flow rates, sulfur hexafluoride will be injected at a high rate into the base of the stack in order to overcome the large dilution factor needed for detection of the tracer at the sampling ports above. If a leak occurs in the gas delivery system, the potential is present for a buildup of $\mathrm{SF}_{6}$ to occur which could approach the 1000 -ppm level. The gas is five times as heavy as air so will accumulate in confined spaces and in low areas. Leak tests of the delivery system will be made at least daily to prevent such an occurrence.

Access to the test ports may require the use of scaffolding or manlifts, either of which will necessitate special training for sampling personnel and any observers. The training requirements will be indicated in the job hazard analysis. This will limit access to the sampling ports to trained personnel.

If the purpose of a given run is to investigate the sensitivity of the COV determination to the tracerinjection location, the test may be invalid if the ending ambient concentration is elevated above that at the start of the test. This would indicate poor dispersion away from the test site and recirculation of the tracer to the inlet of the fan if the stack exhaust point is in view of and is reasonably close to the fan inlet. This may result in a false indication of good mixing.

\subsection{Equipment used for Stack Measurements}

Specific calibration check concentration levels, probe dimensions, measurement grids, flow rates and other special requirements will be provided in the specific Test Instruction. Appendix A provides a typical layout for the test setup. The following are essential items of equipment:

\{tc 13 "Equipment $\}$

- Sulfur hexafluoride calibration check gas

- Sulfur hexafluoride bulk gas

- Bruel and Kjaer Model 1302 Gas analyzer

- Gas regulators and flowmeters

- Gas sampling probe

- Gas injection probe

- Vacuum pump (Sierra) 
- Air velocity meter

The absolute calibration of the Model 1302 Gas Analyzer is not as important as its general response because the concentration data are used in a relative manner in calculating the COV and in plotting the concentrations at the measurement points. The analyzer will be checked for calibration prior to and after the series of tests, and the instrument's response may be checked on a daily basis.

\subsection{Work instructions for Setup, Measurements, and Data Reduction}

The steps taken to setup, configure, and operate the stack fans and test equipment are listed. Based on previous field measurements, the steps are ordered to achieve maximum efficiency in the testing. In addition to these steps, test instructions, which are developed for each test series, provide specific details and operating parameters.

\subsection{Preliminary Steps:}

6.1.1 Provide essential supplies at the sampling location. (gas cylinders and regulators, fittings and probe-port couplers, marking pens, data sheets, writing and probe-supporting platforms).

\subsubsection{Fill in test information on dataform.}

6.1.3 Obtain barometric, temperature, and relative humidity information for the gas analyzer.

6.1.4 Setup the gas analyzer system at the stack sampling port according to the illustrations in Appendices A and B.

Note: The sampling equipment consists of a stainless steel probe with enough length to reach across the inside diameter of the stack, allowing for fittings. The intake end should have a $90^{\circ}$ bend so that the open end of the tube faces downward or into the flow within the stack). The outlet end of the probe should terminate in a tee. One leg of the tee connects by flexible tubing to a rotameter and vacuum pump. This leg should draw from 1- to 10-1pm flow of air, depending on the volumetric flow in the stack. The other leg of the tee connects via flexible tubing to a coarse inline filter (47-mm-diameter glass fiber filter) and then to the Model 1302 gas analyzer inlet. To minimize tubing length to the analyzer, locate the gas analyzer near the test port on the stack. 


\subsection{System Startup}

6.2.1 Start the stack fan, adjust the flow to the velocity called for in the test instruction, and record on the data sheet.

6.2.2 Verify the stack centerline air velocity in the sampling plane using a velocity flow meter, and record value on data sheet.

6.2.3 Turn-on the gas analyzer.

6.2.4 Program the analyzer for:

- 60-second samples,

- continuous operation,

- the current barometric pressure,

- moisture compensation if needed.

Note: Gas analyzer readings can be made with or without water-vapor correction. If the air is sufficiently dry ( $<$ than about $60 \%$ relative humidity) where the water vapor contribution is negligible ( $<$ than about $14.5 \mathrm{E}+03 \mathrm{ppm}$ ), the balance of the readings can be made with water vapor compensation but without water vapor measurement to reduce sample times.

6.2.5 Set the sample probe to the center position.

Note: Mark the sampling probe with a permanent marker so the inlet can be placed at each successive measurement point. The layout for the sample points is given in the test instruction.

Note: Sampling plane traverse points Use the grid of measurement points provided with the tests instruction and dataform. This is usually the same as used for the velocity uniformity test. A centerpoint, is included as a common reference and for graphical purposes. The layout design divides the area of the sampling plane so that each point represents approximately an equal-sized area \{tc U3 "Potential Test Conditions\} 


\subsection{Daily Tracer Gas Background Concentration Measurement}

6.3.1 At the beginning of sampling each day and after the analyzer has stabilized (about 10 minutes), obtain at least 6 consecutive background readings. Do not proceed with the test if the background exceeds $5 \%$ of the anticipated average concentration in the stack.

6.3.2 Record these readings in the logbook designated for the tests.

\subsection{Gas Injection and Sample Collection}

The injection equipment consists of a pressurized cylinder of pure liquid sulfur hexafluoride which converts to gas when released. The setup is shown in the figure in Appendix B and includes a gas regulator, valve, flowmeter (rotameter), flexible tubing, and a stainless steel injection probe with a $90^{\circ}$ bend at the discharge end, which is secured at one of five positions. The connections and fittings should be checked to insure that they are secure and leak free to prevent the loss of gas.

\section{Note: Location of Tracer Gas Injection Points\{tc V13 "Potential Test} Conditions\}

Injection plane -- The tests are repeated using five tracer gas injection points within the injection plane: at the centerpoint and at four orthogonally spaced points. These four points are located near the corners if the duct cross section is rectangular. The distance from these four points to the corner or wall is less than $25 \%$ of the duct's

hydraulic diameter (HD), which is calculated by:

$$
H D=\frac{2 H W}{H+W}
$$

where $\mathrm{H}$ and $\mathrm{W}$ are the height and width of a rectangular duct $(\mathrm{H}$ and $\mathrm{W}$ are the same in a round duct). More specific dimensions are given in the Test

6.4.1 Position the injection probe, according to the test instruction found as Attachment A.

6.4.2 Start injection of the tracer gas and adjust for flow rate specified in the test instruction and note the time. 


\section{Note: Estimation of Sulfur Hexafluoride Injection Rate}

Estimate the $\mathrm{SF}_{6}$ injection rate so the average diluted concentration will be within the range of 10 to $100 \%$ of the concentration of the calibration check gas according to the following equation:

$$
\text { injection flowrate }=\text { stack flowrate } \times \frac{\text { target ppmv }}{10^{6}}
$$

The rotameter reading should be adjusted for the density of the $\mathrm{SF}_{6}$. The air equivalent reading is:

$$
\text { rotameter reading }=k x \text { actual flowrate }
$$

where $k$ is 2.53 (the square-root of the density) for $\mathrm{SF}_{6 .}\{\mathrm{tc} \cup 13$ "Potential Test Conditions\}

6.4.3 On the datasheet label the columns of data according to the directions of the traverses.

6.4.4 Verify that the directional orientations and the numbered sample positions are consistent.

6.4.5 Position the sample probe at each measurement point in succession, and record the reading on the dataform.

Note: Each test relies on one repetition for each measurement point in each traverse direction, repeated three times. The repeats are made as three separate runs and not as three consecutive measurements at each point.

6.4.6 Perform two additional repetitions of Step 6.4.5. above

6.4.7 Switch the tests to the other direction and repeat Steps 6.4.5 and 6.4.6.

6.4.8 Check the data sheet for completeness. 
6.4.9 Record the final:

- Rotameter flow rate

- Time since the start of gas injection

- Pressure in the gas cylinder.

6.4.10 Shutdown the delivery of tracer gas.

6.4.11 Continue operation of the gas analyzer for several minutes to purge any remaining gas through the analyzer.

6.4.12 Measure the background tracer gas concentration and record the levels on the datasheet.

6.4.13 Record any climatic conditions that have changed on the datasheet.

6.4.14 Enter the centerline stack velocity flow on the datasheet.

6.4.15 Record any deviations from the above procedure on the data sheet.

6.4.16 Repeat steps 6.4.1 - 6.4.15 for each run as indicated in the test instruction in Attachment A.

\subsection{Data Recording and Calculations}

Prepare the electronic data sheet on which to enter gas concentration readings and other information relevant to the test (see test instruction).

6.5.1 Review the raw datasheets for completeness.

6.5.2 Enter the data into the electronic datasheet.

6.5.3 Calculate the COV for the run.

Note: The EXCEL datasheet shown in Appendix C is setup to calculate the COV for each tracer gas concentration traverse using the average concentration data from all points in the inner two-thirds of the cross section area of the plane (including the center point). 
6.5.4 Compare the observed COV for each run to the acceptance criterion.

Note: The test is acceptable if the COV is within $\leq 20 \%$ for the inner two-thirds of the stack diameter, and if no point differs from the mean by more than $30 \%$. This is determined by inspection of the average concentration at each measurement point. The COV is 100 times the standard deviation divided by the mean.

6.5.5 Sign and date the datasheet attesting to its validity.

Note: A separate datasheet will be provided and signed-off for each test.

\subsection{Gas Analyzer Calibration Check Steps}

Check the gas analyzer calibration by subjecting the analyzer to sulfur hexafluoride calibration gas. Refer to the analyzer's manual, parts 2 and 4.

6.6.1 Setup the system for gas analysis with the regulator, the valve, flexible tubing, and a tee with one leg exhausting excess gas through a flowmeter and the other leg attached to the inlet of the Model 1302. Program the units of measurement as in Part 4.2.3. Enter the barometric pressure in $\mathrm{mm} \mathrm{Hg}$ pressure, standard temperature (that used by the calibration gas vendor), and the sampling tube length into the environmental setup (Part 4.2.4). Record the information on the data sheet.

6.6.2 Set the Model 1302's clock. Program the analyzer for water compensation but not water measurement at one-minute continuous measurement mode (according to part 4.4.2 in manual). 
6.6.3 Program for a continuous monitoring task (4.2.5), and initiate monitoring (4.2.6).

6.6.4 Monitor room conditions, and record the data for several measurements by sampling zero air or room air for at least five minutes.

Note: If the test location has a buildup of the gas, a zero air cylinder or clean air supply will be needed. The $\mathrm{SF}_{6}$ concentration in the room should be several orders of magnitude below the calibration-gas. These settings optimize the low detection capabilities of the acoustically-based detection system.

\subsubsection{Sample calibration gases (from lowest available}

concentrations to highest) for at least five readings each or until no observable trend is found. Record the identification of the calibration gas used. Record data and results in the Logbook.

Note: Set the calibration gas flow rate high enough to insure that the glass ball in the rotameter does not drop to zero during any of the observed steps of a sample cycle. As the calibration check continues, gas levels exhausted during the check will be released into the room and the $\mathrm{SF}_{6}$ background concentrations will increase as the analyzer is checked. The $\mathrm{SF}_{6}$ reading should be within $10 \%$ of the calibration-gas concentration, and the water content should be much lower than ambient.

6.6.6 Obtain baseline tracer (calibration gas) readings at the end of the calibration check. Record results on the datasheet.

Note: The reading will generally be recorded from the digital concentration display. It may be convenient to record the data on a printer or computer, which can be coupled to the analyzer. See the Manual Part 12 (especially Part 12.2.5) for connecting to a printer in data $\log$ mode. 


\begin{tabular}{|l|ll|}
\hline PNNL Operating Procedure & $\begin{array}{l}\text { Rev. No. 0 } \\
\text { Org. Code: D9T99 }\end{array}$ & $\begin{array}{l}\text { Page 11 of 16 } \\
\text { Procedure No.: EMS-JAG-01 }\end{array}$ \\
\hline \multicolumn{3}{|c|}{ Title: Test to Determine Uniformity of a Tracer Gas at a Sampler Probe } \\
\hline
\end{tabular}

\subsection{Exhibits/Attachments}

Appendix A - Overview of Stack and Injection/Sampling Setups

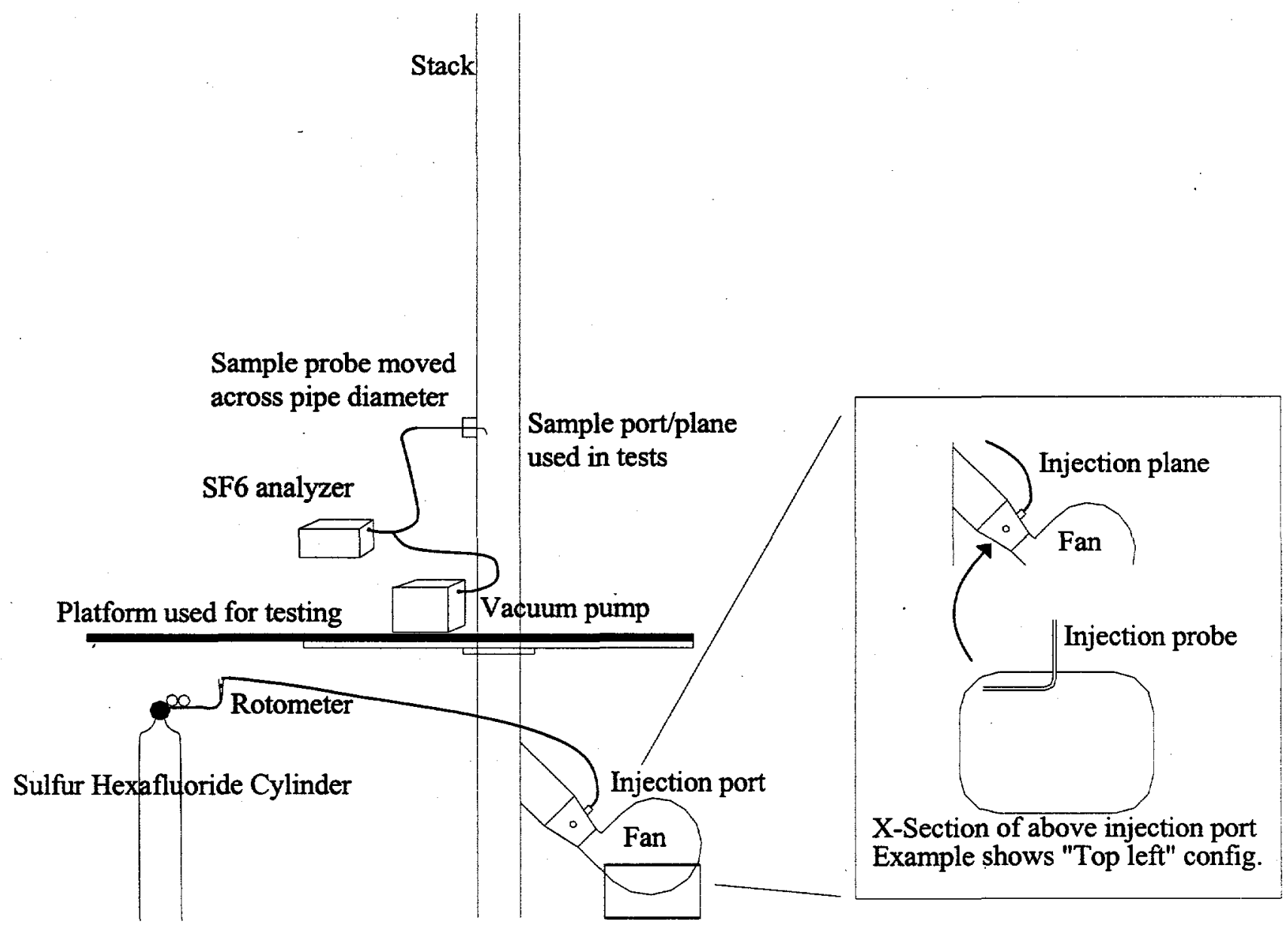


Rev. No. 0

Org. Code: D9T99
Page 12 of 16

Procedure No.: EMS-JAG-01

Title: Test to Determine Uniformity of a Tracer Gas at a Sampler Probe

Appendix B - Details for Stack Sampling Probe and Gas Analyzer Setup

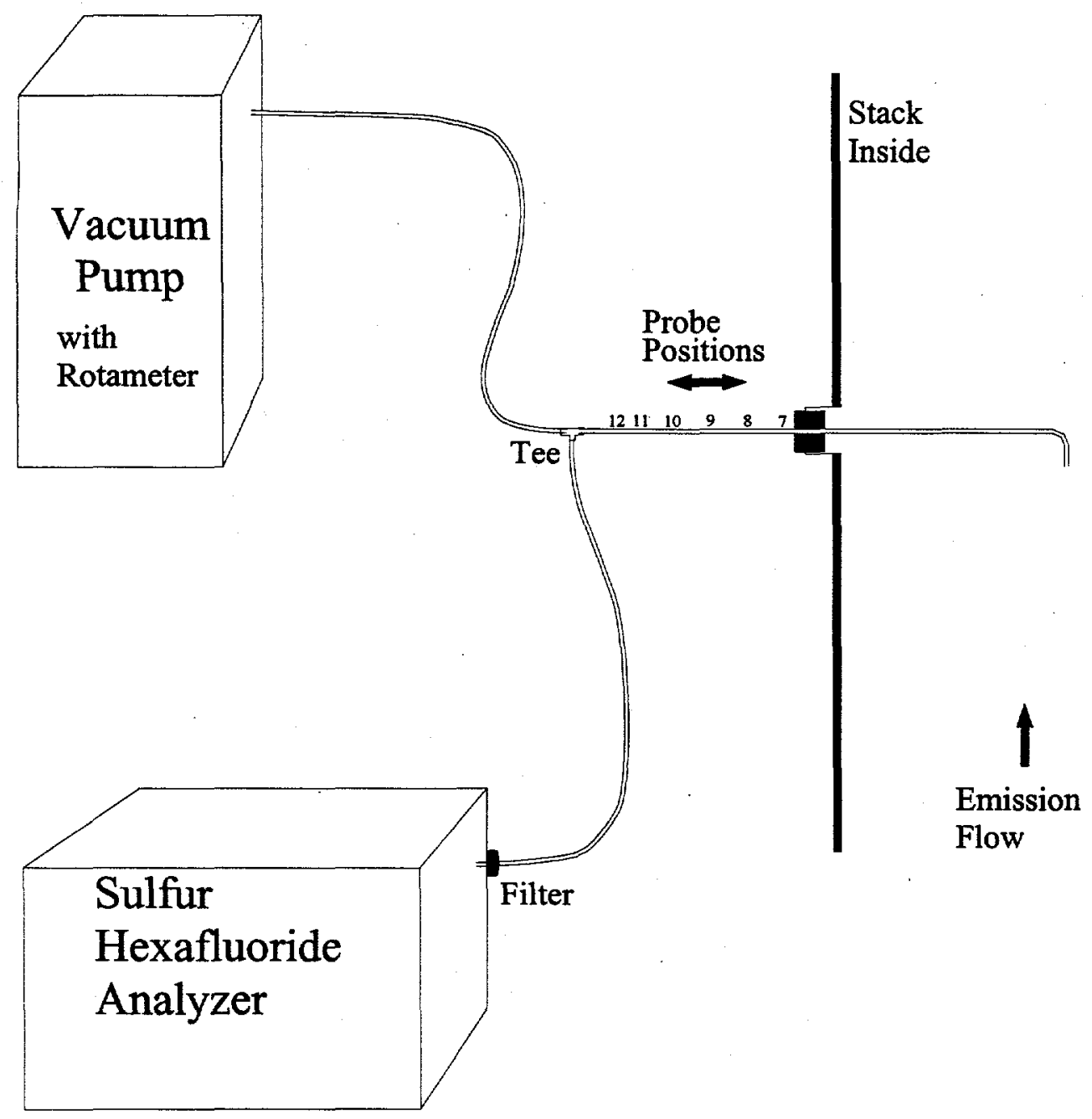

A. 12 


\begin{tabular}{|l|ll}
\hline PNNL Operating Procedure & $\begin{array}{l}\text { Rev. No. 0 } \\
\text { Org. Code: D9T99 }\end{array}$ & $\begin{array}{l}\text { Page 14 of 16 } \\
\text { Procedure No.: EMS-JAG-01 }\end{array}$ \\
\hline
\end{tabular}

Title: Test to Determine Uniformity of a Tracer Gas at a Sampler Probe

Appendix C-Example EXCEL datasheet

TRACER GAS TRAVERSE DATA FORM

\begin{tabular}{|c|c|}
\hline Site & \\
\hline Date & \\
\hline Tester & \\
\hline Stack Dia. & 27.25 in. \\
\hline ack X-Area & 583.2 in. \\
\hline Elevation & \\
\hline e disturbance & in. \\
\hline entration units & $\mathrm{ppm} \mathrm{SF}_{\mathrm{B}}$ \\
\hline
\end{tabular}

Run No. Injection point Fan Setting Stack Temp Start/End Time Center 2/3 from Points in Center $2 / 3$

$\frac{\mathrm{Hz}}{\frac{\operatorname{deg} \mathrm{F}}{2.50}}$

\begin{tabular}{|c|c|}
\hline Point & Depth, in \\
\hline 1 & 1.0 \\
\hline 2 & 1.8 \\
\hline 3 & 3.2 \\
\hline 4 & 4.8 \\
\hline 5 & 6.8 \\
\hline 6 & 9.7 \\
\hline Center & 13.6 \\
\hline 7 & 17.5 \\
\hline 8 & 20.4 \\
\hline 9 & 22.4 \\
\hline 10 & 24.0 \\
\hline 11 & 25.4 \\
\hline 12 & 26.2 \\
\hline
\end{tabular}

Traverse Averages

\begin{tabular}{|l|l|l|l|l|l|l|l|l|}
\hline \multicolumn{2}{|c|}{1} & \multicolumn{2}{c|}{ East } & \multicolumn{5}{c|}{ South } \\
\hline \\
\hline
\end{tabular}

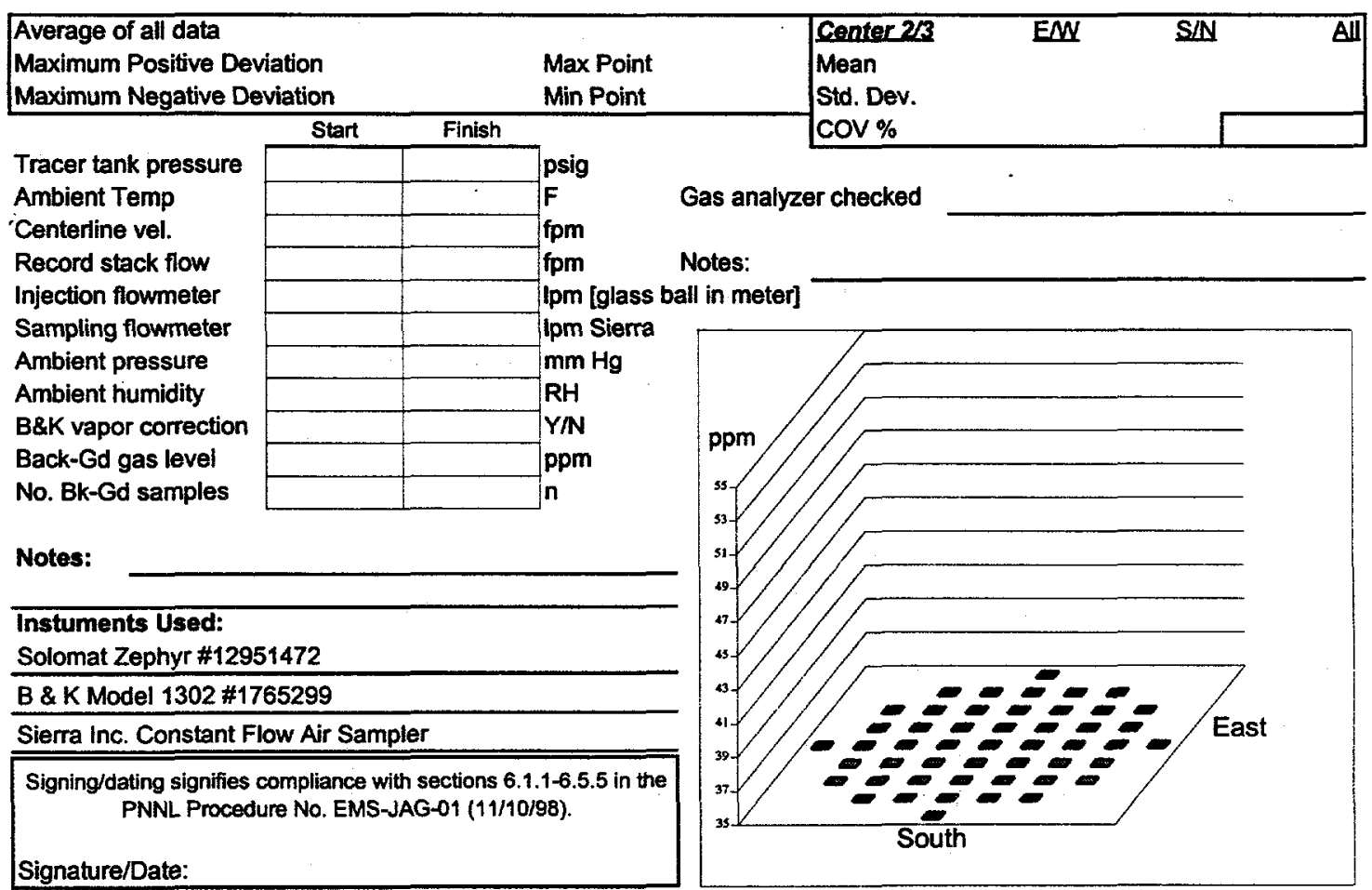




\begin{tabular}{|l|ll|}
\hline PNNL Operating Procedure & $\begin{array}{l}\text { Rev. No. 0 } \\
\text { Org. Code: D9T99 }\end{array}$ & $\begin{array}{l}\text { Page 15 of 16 } \\
\text { Procedure No.: EMS-JAG-01 }\end{array}$ \\
\hline \multicolumn{2}{|c|}{ Title: Test to Determine Uniformity of a Tracer Gas at a Sampler Probe } \\
\hline
\end{tabular}

Attachment A - Illustrative Test Instruction.

A.15 
Title: Test to Determine Uniformity of a Tracer Gas at a Sampler Probe

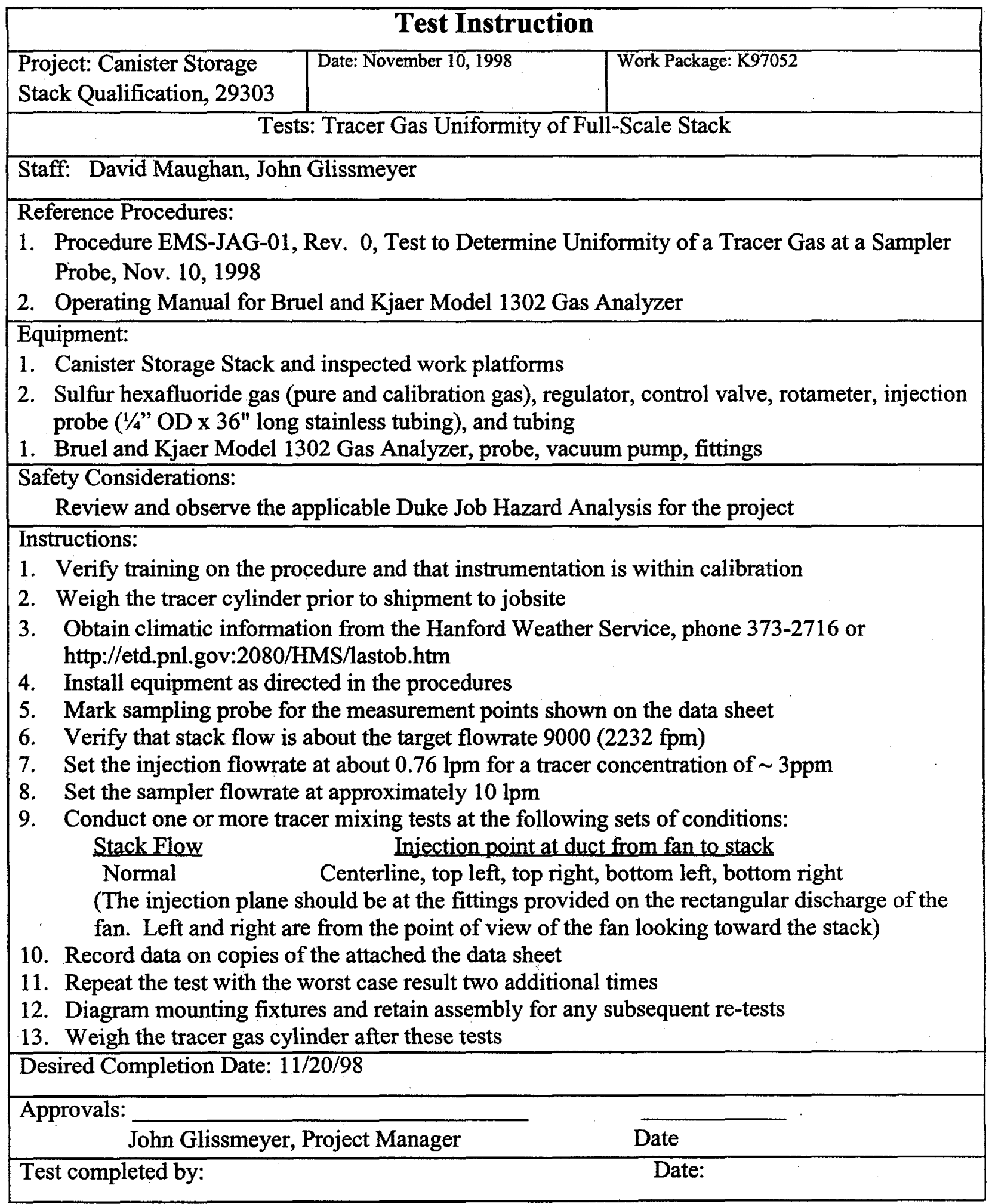


TRACER GAS TRAVERSE DATA FORM

Site CSB

Date 11/20/98

Tester Maughan \& Huckaby

Stack Dia. 27.25 in.

Stack X-Area 583.2 in.

Elevation

El. above disturbance $25^{\prime} 1.25^{\prime \prime}$ in.

Concentration units $\mathrm{ppm} \mathrm{SF}_{6}$
Run No. G20Nov_1, Dup 1(G18Nov_1)

Injection point Center

West Fan Setting (Note $T$

Stack Temp

Start/End Time 8:40 AM to 10:00

Center 2/3 from

Points in Center $2 / 3$

\begin{tabular}{|c|c|c|}
\hline Center & & \\
\hline$\left(\right.$ Note $\left.{ }^{n}\right)$ & & \\
\hline 61 & & \\
\hline $3: 40 \mathrm{AM}$ to $10: 0$ & & \\
\hline 2.50 & to: & 24.75 \\
\hline$\overline{3}$ & to: & $\overline{10}$ \\
\hline
\end{tabular}

Traverse- $\rightarrow$

Trial $\rightarrow$

\begin{tabular}{|c|c|c|}
\hline ria & & 1 \\
\hline Point & Depth, in. & Conc. \\
\hline 1 & & 4 \\
\hline 2 & 1.83 & 4 \\
\hline 3 & 3.22 & 4 \\
\hline 4 & 4.82 & 3. \\
\hline 5 & 6.81 & \\
\hline 6 & 9.70 & 3 \\
\hline Center & 13.63 & 3 \\
\hline 7 & 17.55 & 3 \\
\hline 8 & 20.44 & 3 \\
\hline 9 & 22.43 & 3 \\
\hline 10 & 24.03 & 4 \\
\hline 11 & 25.42 & 4 \\
\hline 12 & 26.25 & 4 \\
\hline
\end{tabular}

Average of all data

Upper Limit $1.3 \times$ mean

Lower Limit $0.7 \times$ mean

${ }_{6}{ }_{6}$

\section{South}

2

3

Mean

Conc.

\begin{tabular}{|l|l|}
\hline 4.43 & Conc. \\
\hline 4.24 & 4.6 \\
\hline & 4.36 \\
\hline
\end{tabular}

4.52

\begin{tabular}{|l|l|}
\hline 28 & 4.08 \\
\hline
\end{tabular}

83

3.8

3.8

32

\begin{tabular}{l|}
.52 \\
3.82
\end{tabular}

82

\begin{tabular}{ll}
3.79 \\
\hline 78
\end{tabular}

4.22

4.22

4.56
3.98

3.98

\begin{tabular}{ll}
\hline 38 & 4.46 \\
\hline
\end{tabular}

4.540

4.27
4.11
4.07

4.360

4.210

4.210

3.973

\begin{tabular}{|l|r|}
3.64 & 3.607 \\
\hline
\end{tabular}

\begin{tabular}{l|r|}
3.46 & 3.400 \\
\hline 3.65 & 3.580 \\
\hline 3.72 & 3.777
\end{tabular}

3.607

4.11
4.12

4.12
4.45

4.02

\begin{tabular}{r|}
4.64 \\
\hline 4.06
\end{tabular}

4.29
4.37
4.51

4.210

\begin{tabular}{l|l|}
\hline 37 & 4.2 \\
\hline
\end{tabular}

\begin{tabular}{l|l|}
\hline .51 & 4.57 \\
\hline .08 & 4.04 \\
\hline
\end{tabular}

\begin{tabular}{l|l}
3.98 & \\
5.18 & Min Point \\
2.79 & Max Point \\
\hline
\end{tabular}

\begin{tabular}{rr|l}
\hline ppm & Dev. from mean & Center 2/3 \\
\hline 3.40 & $14.7 \%$ & Mean \\
4.76 & $-19.5 \%$ & Std. Dev.
\end{tabular}

3.95


TRACER GAS TRAVERSE DATA FORM

Site CSB

Date 11/20/98

Tester Maughan \& Huckaby

Stack Dia. 27.25 in.

Stack X-Area $\quad 583.2$ in.

Elevation

El. above disturbance $25^{\prime} 1.25^{\prime \prime}$ in.

Concentration units $\mathrm{ppm} \mathrm{SF}_{6}$
Run No. G20Nov_2, Dup 2 (G18Nov_1)

Injection point Center

West Fan Setting (Note $1^{*}$ ) $\mathbf{H z}$

Stack Temp 61 deg $F$

Start/End Time 10:45:00 AM to 12:00

Center $2 / 3$ from

Points in Center $2 / 3$
24.75

to: $\quad \frac{24.75}{10}$

Traverse->

Trial $\longrightarrow$

\begin{tabular}{|c|c|c|}
\hline Trial $\longrightarrow$ & & 1 \\
\hline Point & Depth, in. & Conc. \\
\hline 1 & 1.00 & 4 \\
\hline 2 & 1.83 & \\
\hline 3 & 3.22 & 3. \\
\hline 4 & 4.82 & 3.8 \\
\hline 5 & 6.81 & 3. \\
\hline 6 & 9.70 & 3.5 \\
\hline Center & 13.63 & 3 \\
\hline 7 & 17.55 & 3 \\
\hline 8 & 20.44 & 3. \\
\hline 9 & 22.43 & 3 \\
\hline 10 & 24.03 & 3. \\
\hline 11 & 25.42 & 4. \\
\hline 12 & 26.25 & 4. \\
\hline Averages & & $\overline{3}$ \\
\hline
\end{tabular}

1

2

\begin{tabular}{c|c} 
& 3 \\
\hline
\end{tabular}

\begin{tabular}{r|r}
\hline 4.19 & Conc \\
\hline 4.2 & 4.2 \\
\hline 3.96 & 3.9 \\
\hline
\end{tabular}

$4.2 \quad 3.99$

\begin{tabular}{l|l}
3.96 & 3.99 \\
\hline
\end{tabular}

3.84

3.77

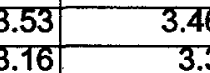

$\begin{array}{ll}3.36 & 3.37\end{array}$

$3.92 \quad 3.58$

\begin{tabular}{c|c}
3.92 & 3.58 \\
\hline 3.92 & 3.9
\end{tabular}

$3.94 \quad 4$.

$4.03 \quad 4.22$

4.29

3.85

4.25

\subsection{5}

\begin{tabular}{l|l}
5.00 & Min Point \\
2.69 & Max Point
\end{tabular}

\begin{tabular}{cr|l} 
ppm & Dev. from mean & Center 2/3 \\
\hline 3.28 & $15.0 \%$ & Mean \\
4.73 & $-22.6 \%$ & Std. Dev.
\end{tabular}

COV as \%

Gas analyzer checked

$11 / 17 / 98$ and $12 / 1 / 98$

Tracer tank pressure

Sample Port Temp

Centerline vel.

Injection flowmeter

CSB Record stack flow

Sampling flowmeter

Ambient pressure

Ambient humidity

B\&K vapor correction

Back-Gd gas level

No. Bk-Gd samples

\begin{tabular}{|c|c|c|}
\hline Start & Finish & \\
\hline 250 & 250 & Jpsig \\
\hline 76 & 76 & $F$ \\
\hline 2537.0 & 2574.0 & fpm \\
\hline 100 & 100 & Ipm Iglass \\
\hline 9050 & 9060 & $\mathrm{fpm}$ \\
\hline 8 & 8 & Ipm Sierra \\
\hline 737.5 & 737.5 & $\mathrm{~mm} \mathrm{Hg}$ \\
\hline 60.0 & 60.0 & $\mathrm{RH}$ \\
\hline no & no & $Y / N$ \\
\hline- & $=$ & $\mathrm{ppm}$ \\
\hline- & - & $n$ \\
\hline
\end{tabular}

Notes:

Tnstuments Used:

Solomat Zephyr \#12951472

B \& K Model 1302 \#1765299

Sierra Inc. Constant Flow Air Sampler

Signing/dating signifies compliance with sections 6.1.1-6.5.5 in the PNNL
Procedure No. EMS-JAG-01 (11/10/98).
Signature/Date: signature on original

Notes:

1*: The CSB fan motor operated as is without adjustment.

\begin{tabular}{rrr}
$\frac{\mathrm{O} / \mathrm{I}}{3.72}$ & $\frac{\mathrm{R} / \mathrm{L}}{3.66}$ & 3.69 \\
0.275 & 0.250 & 0.256 \\
7.4 & 6.8 & $\mathbf{6 . 9}$ \\
\hline
\end{tabular}

Il in meter]

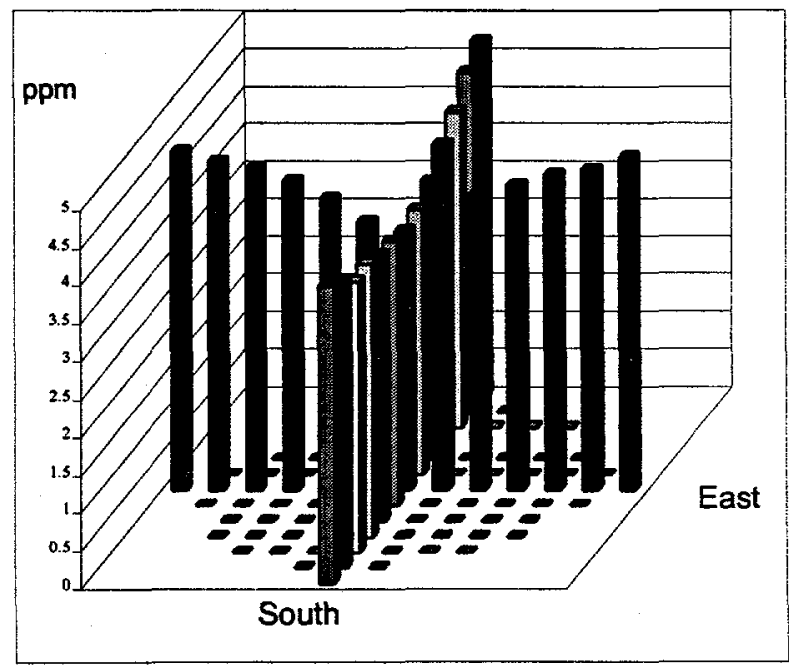


TRACER GAS TRAVERSE DATA FORM

Site CSB

Date 11/18/98

Tester Maughan \& Huckaby

Stack Dia.

Stack X-Area

Elevation

El. above disturbance

Concentration units
27.25 in

583.2 in.

$25^{\prime} 1.25^{\prime \prime}$ in.

ppm $\mathrm{SF}_{6}$
Run No. G18Nov_2

Injection point Upper Right

West Fan Setting (Note $\left.T^{*}\right) \quad H z$

Stack Temp

Start/End Time 1:45 to 3:15

Center $2 / 3$ from

Points in Center 2/3

\begin{tabular}{rr}
\hline 2.50 \\
3
\end{tabular} to: $\quad$ to: $\quad 24.75$

Traverse->

Trial $\rightarrow$ East

\begin{tabular}{|r|c|c|c|c|}
\hline Point & Depth, in. & Conc. & Conc. & Conc. \\
\hline
\end{tabular}

\begin{tabular}{|c|}
\hline Mean \\
\hline mean \\
\hline
\end{tabular}

\begin{tabular}{l|l|}
\hline 3.27 & 3.323 \\
\hline 3.49 & 3.390 \\
\hline
\end{tabular}

\begin{tabular}{l|l|}
3.57 & 3.533 \\
\hline
\end{tabular}

$3.64 \quad 3.650$

\begin{tabular}{r|r|}
3.73 & 3.75 \\
\hline 3.9 & 3.967 \\
\hline
\end{tabular}

\begin{tabular}{|r|r|r|r|r|}
\hline 4 & 4.82 & 3.56 & 3.75 & \\
\hline 5 & 6.81 & 3.81 & 3.73 & 3.7 \\
\hline 6 & 9.70 & 4.02 & 3.98 & \\
\hline Center & 13.63 & 4.3 & 4.35 & \\
\hline
\end{tabular}

\begin{tabular}{|r|r|r|}
\hline Center & 13.63 & 4 \\
\hline 7 & 17.55 & 4.4 \\
\hline 8 & 20.44 & 4.3 \\
\hline 9 & 22.43 & 4.0 \\
\hline 10 & 24.03 & 3.8 \\
\hline 11 & 25.42 & 3.7 \\
\hline 12 & 26.25 & 3.5 \\
\hline
\end{tabular}

Averages

\begin{tabular}{l|l|}
47 & 4.48 \\
\hline
\end{tabular}

\begin{tabular}{ll}
4.36 & 4.33 \\
\hline 4.05 & 4.02
\end{tabular}

$3.8 \quad 3.81$

\begin{tabular}{l|l}
3.8 & 3.81 \\
3.79 & 3.79
\end{tabular}

\begin{tabular}{l|l}
3.55 & 3.72 \\
\hline 3.83 & 3.87 \\
\hline
\end{tabular}

\begin{tabular}{r|r}
\hline 3.9 & 3.967 \\
\hline 4.36 & 4.33 \\
\hline
\end{tabular}

\begin{tabular}{l|l|}
4.45 & 4.467 \\
\hline
\end{tabular}

\begin{tabular}{l|l|}
4.34 & 4.343 \\
\hline
\end{tabular}

\begin{tabular}{l|l|}
\hline 4.15 & 4.073 \\
\hline 3.84 & 3.817 \\
\hline
\end{tabular}

\begin{tabular}{l|l|}
3.61 & 3.730 \\
\hline
\end{tabular}

\begin{tabular}{l|l}
3.66 & 3.643 \\
\hline
\end{tabular}

3.8

\begin{tabular}{|c|c|c|c|c|c|c|c|c|}
\hline Average of all data & 3.91 & & $\mathrm{ppm}$ & Dev. from mean & Center 2/3 & $\mathrm{O} / \mathrm{I}$ & $R / L$ & All \\
\hline Upper Limit $1.3 \times$ mean & 5.09 & Min Point & 3.32 & $13.2 \%$ & Mean & 3.99 & 4.10 & $4 . \overline{05}$ \\
\hline Lower Limit $0.7 \times$ mean & 2.74 & Max Point & 4.47 & $-16.7 \%$ & Std. Dev. & 0.333 & 0.154 & 0.258 \\
\hline & & & & & COV as $\%$ & 8.3 & 3.8 & 6.4 \\
\hline
\end{tabular}

Tracer tank pressure Sample Port Temp Centerline vel. Injection flowmeter CSB Record stack flow Sampling flowmeter Ambient pressure Ambient humidity B\&K vapor correction Back-Gd gas level No. Bk-Gd samples

\begin{tabular}{|c|c|c|}
\hline Start & Finish & \\
\hline 250 & 250 & psig \\
\hline 58 & 58 & $F$ \\
\hline 2524.0 & 2579.0 & fpm \\
\hline 100 & 102.5 & Ipm [glass \\
\hline 9140 & 9130 & $\mathrm{fpm}$ \\
\hline 8 & 8 & Ipm Sierra \\
\hline 746.7 & 746.7 & $\mathrm{~mm} \mathrm{Hg}$ \\
\hline 45.0 & 45.0 & RH \\
\hline no & no & $Y / N$ \\
\hline- & - & ppm \\
\hline- & - & $n$ \\
\hline
\end{tabular}

Notes:

Instuments Used:

Solomat Zephyr \#12951472

B \& K Model 1302 \#1765299

Sierra Inc. Constant Flow Air Sampler

Signing/dating signifies compliance with sections 6.1.1-6.5.5 in the PNNL Procedure No. EMS-JAG-01 (11/10/98)

Signature/Date: signature on original
Gas analyzer checked

$11 / 17 / 98$ and $12 / 1 / 98$

Notes: Leak test of delivery system done $=$ no leaks.

$1^{*}$ : The CSB fan motor operated as is without adjustment.

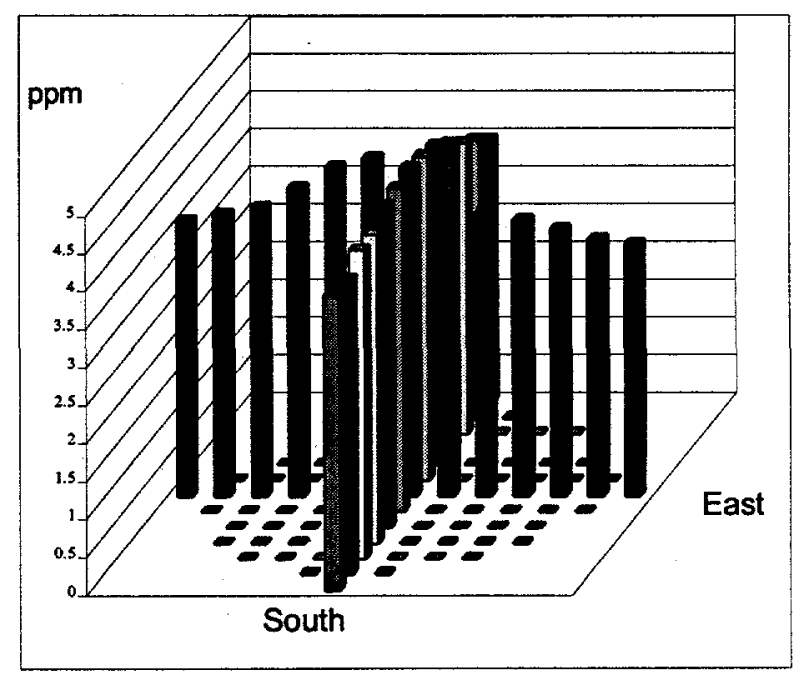


TRACER GAS TRAVERSE DATA FORM

Site CSB

Date 11/19/98

Tester Maughan \& Huckaby

Stack Dia.

Stack X-Area

Elevation

El. above disturbance

Concentration units
27.25 in.

$25^{\prime} 1.25^{\prime \prime}$ in. $\mathrm{ppm} \mathbf{S F}_{6}$
Run No. G19Nov_1

Injection point Lower Lêft

West Fan Setting (Note $\left.T^{*}\right)$

Stack Temp

Start/End Time 8:00 am to 9:30

Center $2 / 3$ from

Points in Center $2 / 3$

Traverse $\longrightarrow$

Trial $\rightarrow$

Point Depth, in

to: 24.75

to: 10

\begin{tabular}{|c|c|c|c|c|c|c|c|c|c|}
\hline Trial --> & & 1 & 2 & 3 & Mean & 1 & 2 & 3 & Mean \\
\hline Point & Depth, in. & Conc. & Conc. & Conc. & Conc. & Conc. & Conc. & Conc. & Conc. \\
\hline 1 & 1.00 & 3.81 & 3.7 & 3.78 & 3.763 & 3.8 & 3.78 & 3.85 & 3.810 \\
\hline 2 & 1.83 & 3.75 & 3.75 & 3.88 & 3.793 & 3.92 & 3.85 & 3.87 & 3.880 \\
\hline 3 & 3.22 & 3.76 & 3.84 & 3.8 & 3.800 & 3.78 & 3.86 & 3.87 & 3.837 \\
\hline 4 & 4.82 & 3.92 & 3.95 & 3.9 & 3.923 & 3.92 & 3.96 & 3.83 & 3.903 \\
\hline 5 & 6.81 & 4.06 & 3.97 & 3.9 & 3.977 & 3.91 & 3.93 & 4.04 & 3.960 \\
\hline 6 & 9.70 & 3.96 & 3.93 & 3.99 & 3.960 & 3.99 & 4.03 & 3.94 & 3.987 \\
\hline Center & 13.63 & 3.99 & 4.03 & 4.05 & 4.023 & 3.92 & 4.09 & 3.99 & 4.000 \\
\hline 7 & 17.55 & 4.02 & 4.05 & 4.14 & 4.070 & 3.87 & 3.96 & 3.99 & 3.940 \\
\hline 8 & 20.44 & 3.95 & 3.91 & 3.98 & 3.947 & 4.06 & 3.95 & 3.94 & 3.983 \\
\hline 9 & 22.43 & 3.77 & 3.87 & 3.83 & 3.823 & 4 & 3.9 & 3.9 & 3.933 \\
\hline 10 & 24.03 & 3.85 & 3.78 & 3.8 & 3.810 & 3.85 & 3.99 & 3.85 & 3.897 \\
\hline 11 & 25.42 & 3.77 & 3.65 & 3.68 & 3.700 & 3.84 & 3.85 & 3.79 & 3.827 \\
\hline 12 & 26.25 & 3.75 & 3.55 & & 3.650 & 3.71 & 3.64 & 3.6 & 3.650 \\
\hline Áverages & & 3.87 & 3.84 & 3.89 & 3.865 & 3.89 & 3.91 & 3.88 & 3.893 \\
\hline
\end{tabular}

\begin{tabular}{|c|c|c|c|c|c|c|c|c|}
\hline Average of all data & 3.88 & & $\mathrm{ppm}$ & Dev. from mean & Center $2 / 3$ & $\mathrm{O} / \mathrm{I}$ & RlL & III) \\
\hline Upper Limit 1.3 x mean & 5.04 & Min Point & 3.65 & $5.8 \%$ & Mean & 3.93 & 3.94 & 3.9 \\
\hline Lower Limit $0.7 \times$ mean & 2.72 & Max Point & 4.07 & $-5.1 \%$ & Std. Dev. & 0.096 & 0.052 & 0.07 \\
\hline
\end{tabular}

Tracer tank pressure Sample Port Temp

Centerline vel.

Injection flowmeter

CSB Record stack flow

Sampling flowmeter

Ambient pressure

Ambient humidity

B\&K vapor correction

Back-Gd gas level

No. Bk-Gd samples

\begin{tabular}{|c|c|c|}
\hline Start & Finish & \\
\hline 250 & 250 & psig \\
\hline 59 & 59 & $F$ \\
\hline 2591.0 & 2567.0 & fpm \\
\hline 100 & 101.5 & ipm lglass \\
\hline 9190 & 9175 & fpm \\
\hline 8 & 8 & Ipm Sierra \\
\hline 746.7 & 746.7 & $\mathrm{~mm} \mathrm{Hg}$ \\
\hline 89.0 & 89.0 & RH \\
\hline no & no & $Y / N$ \\
\hline 3.54 & - & ppo \\
\hline 6 & - & ln \\
\hline
\end{tabular}

Notes:

\section{Instuments Used:}

Solomat Zephyr \#12951472

B \& K Model 1302 \#1765299

Sierra inc. Constant Flow Air Sampler

Signing/dating signifies compliance with sections 6.1.1-6.5.5 in the PNNL
Procedure No. EMS-JAG-01 (11/10/98).
Signature/Date: signature on original

Gas analyzer checked $\quad 11 / 17 / 98$ and 12/1/98

Notes: Tent temp. $\sim=60 \mathrm{deg}$.

1*: The CSB fan motor operated as is without adjustment.

all in meter]

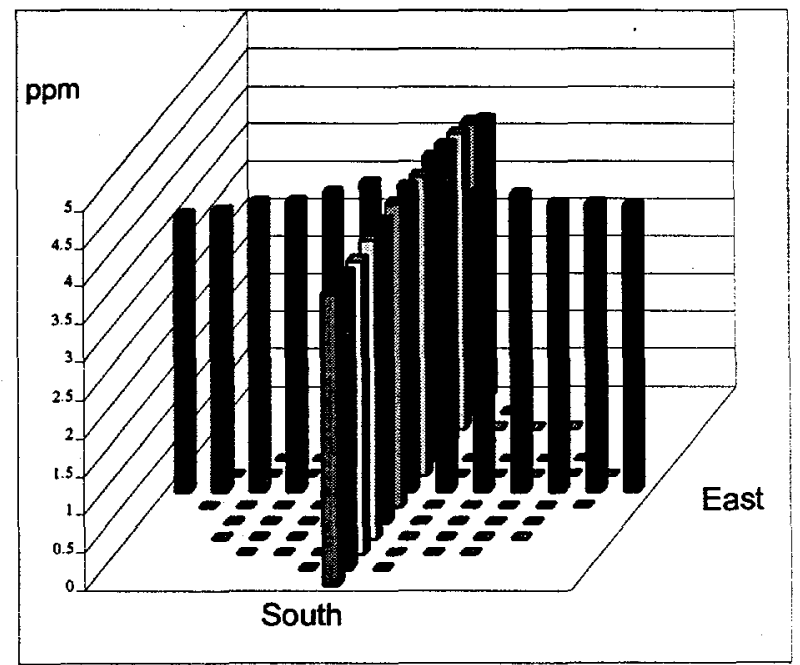


TRACER GAS TRAVERSE DATA FORM

Site CSB

Date 11/19/98

Tester Maughan \& Huckaby

Stack Dia.

Stack X-Area

Elevation

El. above disturbance

Concentration units

Traverse->

Trial $\rightarrow$
Run No. G19Nov_2

Injection point Lower Right

West Fan Setting (Note $\left.{ }^{*}\right) \quad \mathrm{Hz}_{\mathrm{z}}$ Stack Temp $59 \mathrm{deg} F$

Start/End Time 9:55 am to 11:30 am

Center 2/3 from

Points in Center $2 / 3$
24.75

10

\begin{tabular}{|c|c|c|c|c|c|c|c|c|c|}
\hline Trial & & 1 & 2 & 3 & Mean & 1 & 2 & 3 & Mean \\
\hline Point & Depth, in. & Conc. & Conc. & Conc. & Conc. & Conc. & Conc. & Conc. & Conc. \\
\hline 1 & 1.00 & 4.14 & 4.15 & 4.08 & 4.123 & 4.06 & 4.25 & 4.06 & 4.123 \\
\hline 2 & 1.83 & 4.39 & 4.42 & 4.24 & 4.350 & 4.03 & 3.99 & 4.09 & 4.037 \\
\hline 3 & 3.22 & 4.27 & 4.27 & 4.36 & 4.300 & 3.95 & 3.91 & 4.02 & 3.960 \\
\hline 4 & 4.82 & 4.23 & 4.16 & 4.43 & 4.273 & 3.93 & 3.93 & 3.96 & 3.940 \\
\hline 5 & 6.81 & 4.43 & 4.12 & 4.04 & 4.197 & 3.99 & 3.88 & 3.87 & 3.913 \\
\hline 6 & 9.70 & 4 & 4.12 & 4.14 & 4.087 & 3.95 & 3.81 & 3.73 & 3.830 \\
\hline Center & 13.63 & 3.82 & 3.75 & 3.81 & 3.793 & 3.87 & 3.6 & 3.8 & 3.757 \\
\hline 7 & 17.55 & 3.5 & 3.64 & 3.65 & 3.597 & 3.88 & 3.72 & 3.77 & 3.790 \\
\hline 8 & 20.44 & 3.52 & 3.59 & 3.41 & 3.507 & 3.83 & 3.87 & 3.8 & 3.833 \\
\hline 9 & 22.43 & 3.45 & 3.53 & 3.54 & 3.507 & 3.81 & 3.81 & 3.8 & 3.807 \\
\hline 10 & 24.03 & 3.6 & 3.46 & 3.46 & 3.507 & 3.88 & 3.77 & 3.96 & 3.870 \\
\hline 11 & 25.42 & 3.4 & 3.41 & 3.37 & 3.393 & 3.73 & 3.81 & 3.82 & 3.787 \\
\hline 12 & 26.25 & 3.38 & 3.38 & 3.42 & 3.393 & 3.79 & 3.75 & 3.73 & 3.757 \\
\hline \multicolumn{2}{|c|}{ Averages $\longrightarrow$} & 3.86 & 3.85 & 3.84 & 3.848 & 3.90 & 3.85 & 3.88 & 3.877 \\
\hline \multirow{3}{*}{\multicolumn{2}{|c|}{$\begin{array}{l}\text { Average of all data } \\
\text { Upper Limit } 1.3 \times \text { mean } \\
\text { Lower Limit } 0.7 \times \text { mean }\end{array}$}} & 3.86 & & \multicolumn{2}{|c|}{ Dev. from mean } & Center 2/3 & $\mathrm{O} / 1$ & \multirow{2}{*}{$\frac{R / L}{386}$} & All \\
\hline & & 5.02 & Min Point & 3.39 & $12.0 \%$ & Mean & $3 \overline{86}$ & & $3 . \overline{86}$ \\
\hline & & 2.70 & Max Point & 4.35 & $-12.8 \%$ & \multirow{2}{*}{$\begin{array}{l}\text { Std. Dev. } \\
\text { COV as \% }\end{array}$} & 0.350 & $\begin{array}{r}3.86 \\
0.070\end{array}$ & 0.245 \\
\hline & & & & & & & 9.0 & $\begin{array}{r}0.070 \\
1.8\end{array}$ & 6.3 \\
\hline
\end{tabular}

Tracer tank pressure Sample Port Temp

Centerline vel. Injection flowmeter CSB Record stack flow Sampling flowmeter Ambient pressure Ambient humidity B\&K vapor correction Back-Gd gas level No. Bk-Gd samples

\begin{tabular}{|c|c|c|}
\hline Start & Finish & \\
\hline 250 & 250 & psig \\
\hline 62 & 62 & $F$ \\
\hline 2567.0 & 2650.0 & fpm \\
\hline 101.5 & 101.5 & Ipm [glass \\
\hline 9170 & 9180 & fpm \\
\hline 8 & 8 & Ipm Sierra \\
\hline 749.6 & 749.6 & $\mathrm{~mm} \mathrm{Hg}$ \\
\hline 62.0 & 62.0 & RH \\
\hline no & no & $Y I N$ \\
\hline- & - & ppm \\
\hline- & - & $n$ \\
\hline
\end{tabular}

Gas analyzer checked

$11 / 17 / 98$ and $12 / 1 / 98$

Notes:

$1^{*}$ : The CSB fan motor. operated as is without adjustment.

Notes:

\section{Instuments Used:}

Solomat Zephyr \#12951472

B \& K Model 1302 \#1765299

Sierra Inc. Constant Flow Air Sampler

Signing/dating signifies compliance with sections 6.1.1-6.5.5 in the PNNL Procedure No. EMS-JAG-01 (11/10/98).

Signature/Date: signature on original

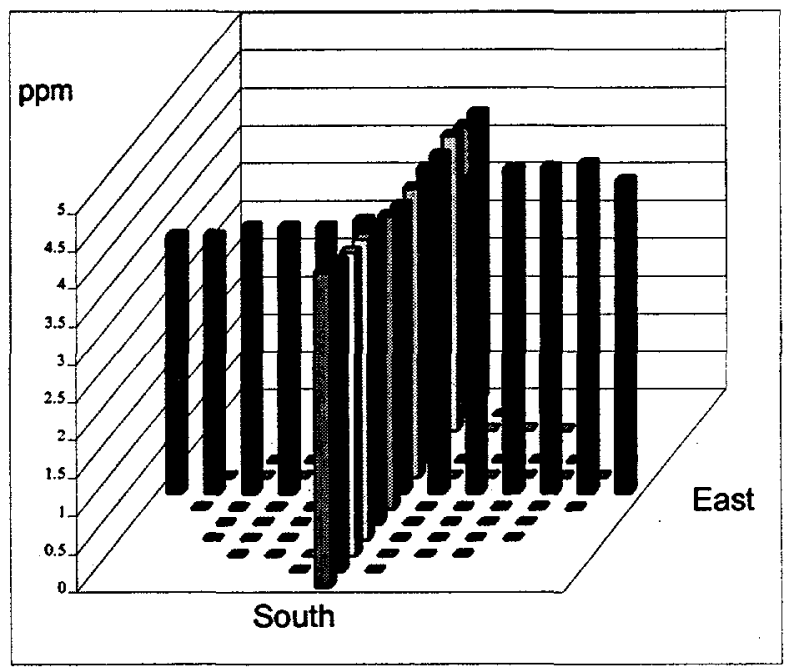


TRACER GAS TRAVERSE DATA FORM

Site CSB

Date 11/19/98

Tester Maughan \& Huckaby

Stack Dia. 27.25 in.

Stack X-Area 583.2 in.

Elevation

El. above disturbance $25^{\prime} 1.25^{\prime \prime}$ in.

Concentration units $\mathrm{ppm} \mathrm{SF}_{6}$
Run No. G19Nov_3

Injection point Upper Left

West Fan Setting (Note $T^{*} \mathrm{~Hz}_{\mathrm{z}}$

Stack Temp

Start/End Time 2:40 to 4:05 pm

Center $2 / 3$ from

Points in Center $2 / 3$

\begin{tabular}{rll}
$\frac{2.50}{3}$ & to: & 24.75 \\
\hline
\end{tabular}

Traverse->

Trial $\longrightarrow$

\begin{tabular}{|r|r|r|}
\hline Point & Depth, in. & Conc. \\
\hline 1 & 1.00 & 4 \\
\hline 2 & 1.83 & 4 \\
\hline 3 & 3.22 & \\
\hline 4 & 4.82 & 4 \\
\hline 5 & 6.81 & 4 \\
\hline 6 & 9.70 & 3 \\
\hline Center & 13.63 & 3 \\
\hline 7 & 17.55 & 3 \\
\hline 8 & 20.44 & 3 \\
\hline 9 & 22.43 & 3 \\
\hline 10 & 24.03 & 3 \\
\hline 11 & 25.42 & 3 \\
\hline 12 & 26.25 & 3 \\
\hline Averages & & 3 \\
\hline
\end{tabular}

East

Average of all data

Upper Limit $1.3 \times$ mean ast

Lower Limit $0.7 \times$ mean

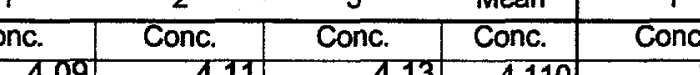

$4.18 \quad 4.05$

$4.1 \quad 4.15$

4.094 .11

\begin{tabular}{ll}
4.03 & 4.01 \\
\hline 3.98 & 3.99
\end{tabular}

$3.97 \quad 3.8$

$3.84 \quad 3.75$

\begin{tabular}{l|l|}
\hline 3.77 & 3.78 \\
\hline 3.68 & 3.74 \\
\hline
\end{tabular}

\begin{tabular}{l|l|}
\hline 3.68 & 3.74 \\
\hline 3.74 & 3.7 \\
\hline
\end{tabular}

\begin{tabular}{l|l|}
\hline 3.68 & 3. \\
\hline 3.69 & 3.68 \\
\hline
\end{tabular}

\begin{tabular}{ll}
3.91 & 3.89 \\
\hline
\end{tabular}

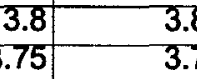

\begin{tabular}{rr|r}
\hline 78 & 3.77 & 3.78 \\
\hline
\end{tabular}

\begin{tabular}{|r|r|r|}
\hline 3.78 & 3.8 & 3.78 \\
\hline 3.74 & 3.79 & 3.73 \\
\hline 3.71 & 3.79 & 3.74 \\
\hline
\end{tabular}

\begin{tabular}{l|l|l|}
\hline .73 & 3.76 & 3.723 \\
\hline
\end{tabular}

\begin{tabular}{|l|l|l|}
\hline 3.68 & 3.6 & 3.657 \\
\hline
\end{tabular}

\begin{tabular}{l|lrr|l}
3.90 & & ppm & Dev. from mean & Center 2/3 \\
5.07 & Min Point & 3.66 & $6.5 \%$ & Mean \\
2.73 & Max Point & 4.15 & $-6.2 \%$ & Std. Dev.
\end{tabular}

COV as \%

Gas analyzer checked $\quad 11 / 17 / 98$ and 12/1/98

Temt temp. about 62 deg.

Tracer tank pressure

Sample Port Temp

Centerline vel.

Injection flowmeter

CSB Record stack flow

Sampling flowmeter

Ambient pressure

Ambient humidity

B\&K vapor correction

Back-Gd gas level

No. Bk-Gd samples

\begin{tabular}{|c|c|c|}
\hline Start & Finish & \\
\hline 250 & 250 & psig \\
\hline 60 & 62 & $F$ \\
\hline 2598.0 & 2497.0 & fpm \\
\hline 100 & 102 & Ipm [glass \\
\hline 9170 & 9170 & $\mathrm{fpm}$ \\
\hline 8 & 8 & Ipm Sierra \\
\hline 747.6 & 747.6 & $\mathrm{~mm} \mathrm{Hg}$ \\
\hline 65.0 & 65.0 & $\mathrm{RH}$ \\
\hline no & no & $\mathrm{Y} / \mathrm{N}$ \\
\hline- & - & ppm \\
\hline- & $=$ & \\
\hline
\end{tabular}

Notes:

Instuments Used:

Solomat Zephyr \#12951472

B \& K Model 1302 \#1765299

Sierra Inc. Constant Flow Air Sampler

Signing/dating signifies compliance with sections 6.1.1-6.5.5 in the PNNL
Procedure No. EMS-JAG-01 (11/10/98).
Signature/Date: signature on original

Notes: No leaks detected in gas delivery equipment.

$1^{*}$ : The CSB fan motor operated as is without adjustment.

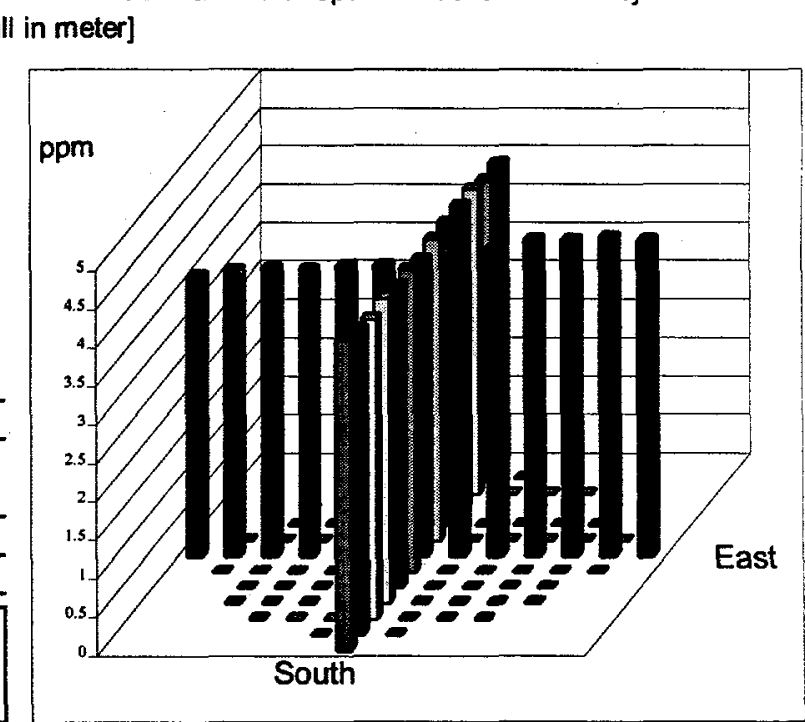




\section{Reference}

40 CFR 61, Subpart H, U.S. Environmental Protection Agency, "National Emission Standards for Emissions of Radionuclides Other than Radon from Department of Energy Facilities." Code of Federal Regulations. 


\section{Appendix B}

Test to Determine the Uniformity of Tracer Particles 


\begin{tabular}{|c|c|c|c|}
\hline \multicolumn{4}{|c|}{ PRIVATE } PNNL Operating Procedure \\
\hline $\begin{array}{l}\text { Title: Test to Determine } \\
\text { Uniformity of a Tracer } \\
\text { Aerosol at a Sampler } \\
\text { Probe\{PRIVATE }\}\end{array}$ & $\begin{array}{l}\text { Org. Code: } \\
\text { Procedure No. } \\
\text { Rev. No.: }\end{array}$ & $\begin{array}{l}\text { D9T } \\
\text { EM } \\
0\end{array}$ & \\
\hline Work Location： General & Effective Date: & \multicolumn{2}{|c|}{ November 10,1998} \\
\hline Author: John A. Glissmeyer & \multicolumn{3}{|c|}{ Supersedes Date: } \\
\hline $\begin{array}{l}\text { Identified Hazards: } \\
\text { Radiological } \\
\text { Hazardous Materials } \\
\text { - Physical Hazards } \\
\text { Hazardous Environment } \\
\text { Other: }\end{array}$ & \multicolumn{3}{|c|}{$\begin{array}{l}\text { Identified Use Category: } \\
\text { Mandatory Use } \\
\text { Continuous Use } \\
\text { Reference Use } \\
\text { Information Use }\end{array}$} \\
\hline \multicolumn{4}{|c|}{ Are One-Time Modifications Allowed? $\square$ Yes No } \\
\hline Person Signing & \multicolumn{2}{|c|}{ Signature } & Date \\
\hline $\begin{array}{l}\text { Technical review: } \\
\text { James L. Huckaby }\end{array}$ & & & \\
\hline $\begin{array}{l}\text { Project Manager: } \\
\text { John Glissmeyer }\end{array}$ & & & \\
\hline $\begin{array}{l}\text { Line Manager: } \\
\text { James Droppo }\end{array}$ & & & \\
\hline Concurrence: & & & \\
\hline $\begin{array}{l}\text { Quality Engineer: } \\
\text { Thomas G. Walker }\end{array}$ & & & \\
\hline
\end{tabular}

B. 1 


\begin{tabular}{|c|ll|}
\hline PNNL Operating Procedure & $\begin{array}{l}\text { Rev. No. } 0 \\
\text { Org. Code: D9T99 }\end{array}$ & $\begin{array}{l}\text { Page 2 of 15 } \\
\text { Procedure No.: EMS-JAG-02 }\end{array}$ \\
\hline \multicolumn{2}{|c|}{ Title: Test to Determine Uniformity of a Tracer Aerosol at a Sampler Probe } \\
\hline
\end{tabular}

\subsection{Purpose}

The performance of new stack sampling systems must be shown to satisfy the requirements of 40 CFR 61, Subpart H, "National Emission standards for Emissions of Radionuclides Other than Radon from Department of Energy Facilities." This regulation governs portions of the design and implementation of effluent air sampling. The stack sampler performance is adequately characterized when potential contaminants in the effluent are of a uniform concentration at the sampling location (plane) and line losses are within acceptable limits. This procedure determines whether the concentration of aerosol particulate contaminants is uniformly distributed in the area of the sampling probe. Other procedures address flow angle, uniformity of gas velocity, and uniformity of gas contaminants. A contaminant concentration that is uniform at the sampling plane enables the extraction of samples that represent the true emission concentration.

The uniformity is expressed as the variability of the measurements about the mean. This is expressed using the relative coefficient of variance (COV), which is the standard deviation divided by the mean and expressed as a percentage. The lower the COV value, the more uniform the velocity. The acceptance criterion is that the COV of the air velocity be $\leq 20 \%$ across the center two-thirds of the area of the stack. This allows for slightly more than a 2:1 variability in velocity measurements in the stack cross section.

\subsection{Applicability}

This procedure can be used in the field or on modeled stacks to determine whether air-sampling probes can collect representative samples under normal operations. The tests are applicable to effluent stacks or ducts within the following constraints:

- The aerosol particulate tests are generally limited to stacks with flowrates greater than 50 cubic feet per minute range. The upper bound of flowrate is determined by the output capacity of the aerosol generator; the background reading for particulate aerosols, and the operational detection range of the counters for particulates.

- Environmental constraints -- optical particle counters will require the use of a controlled temperature environment to maintain the equipment above 55 degrees Fahrenheit.

\subsection{Prerequisites and Conditions}

Conditions and concerns that must be satisfied prior to sampling are listed below:

- Safety glasses, hard toed or substantial shoes are required in work areas.

- Scaffold user training may be required to access the sampling ports of the stack.

- Alcohol will be used for equipment cleanup. A flammable equipment storage cabinet is required to hold chemicals. Material Safety Data Sheets must be provided.

- Air pressure (up to about $75 \mathrm{psi}$ ) is used to aerosolize oil into fine particles. Knowledge of the use and operation of pressurized air-lines, and the careful observations of any build-up of oil mist outside of the generator is essential to prevent exceeding ACGIH levels listed below. 


\begin{tabular}{|l|ll|}
\hline PNNL Operating Procedure & $\begin{array}{l}\text { Rev. No. } 0 \\
\text { Org. Code: D9T99 }\end{array}$ & $\begin{array}{l}\text { Page 3 of 15 } \\
\text { Procedure No.: EMS-JAG-02 }\end{array}$ \\
\hline \multicolumn{2}{|c|}{ Title: Test to Determine Uniformity of a Tracer Aerosol at a Sampler Probe } \\
\hline
\end{tabular}

- Knowledge for the setup, use of, and operation of flowmeters, particle counters, and computers is essential.

- The job-hazards analysis must be followed.

\subsection{Precautions and Limitations}

\section{Caution: The American Conference of Governmental Industrial Hygienists (ACGIH) 8-hour time- weighted average limit for human exposure to mineral oil mist is $5 \mathrm{mg} / \mathrm{m}^{3}$. It is odorless.}

During tests of stacks with high flow rates, oil droplets will be injected into the base of the stack in order to overcome the large dilution factor needed for detection of selected particles at the sampling ports above. The potential is present for a buildup of oil mist to occur outside of the aerosol generator that could approach the $5 \mathrm{mg} / \mathrm{m}^{3}$ caution level. The undiluted mist is heavier than air so may accumulate in confined spaces and in low areas if allowed to escape. Leak tests of the delivery system will be made at least daily to prevent such an occurrence.

Access to the test ports may require the use of scaffolding or manlifts, either of which will necessitate special training for sampling personnel and any observers. The training requirements will be indicated in the job hazard analysis.

The test may be invalid if the ending ambient concentration of mist is elevated above that observed at the start of the test. This would indicate poor dispersion away from the test site caused by recirculation of the tracer to the inlet of the fan and will only occur if the stack exhaust point is in view of and is reasonably close to the fan inlet. This may result in a false indication of good mixing.

\subsection{Equipment used for Stack Measurements}

Specific calibration check concentration levels, probe dimensions, measurement grids, flow rates and other special requirements will be provided in the specific Test Instruction. Appendix A provides a typical layout for the test setup. The following are essential items of equipment:

\{tc 13 "Equipment\}

- Vacuum pump oil,

- Oil mist generator,

- Compressed air, lines, and precision air regulators,

- Oil mist injection probe,

- Aerosol sampling probes,

- Mechanism for accurate placement of sampling probe,

- Optical particle counters,

- Computers linked to particle counters,

- Velocity flow measurement meter. 
Title: Test to Determine Uniformity of a Tracer Aerosol at a Sampler Probe

Two optical particle counters (OPCs) will be used simultaneously to count particles that are approximately in the10-micron size range. A mobile OPC is designated to make point-by-point measurements in the orthogonal traverses. A reference OPC is used to note trends in aerosol generator output over time and to validate the mobile sampler results. The operation of the reference OPC, at some fixed position in the stack, may be contingent on whether or not a suitable port is available on the test stack.

The counters, re-checked annually for calibration by the manufacturer, are synchronized for time, sample mode, flow, and count range to monitor their field performance. The absolute calibration of the OPCs is not as important as the general response because the concentration data are used in a relative manner in calculating the $\mathrm{COV}$ and in plotting the concentrations at the measurement points.

The aerosol generator siphons oil from a reservoir and forces the air/oil mixture through a spray nozzle for production of polydisperse particles. Non-hazardous oil with a low vapor pressure (such as vacuum pump oil) should be used in the reservoir. The quantity of aerosol generated is controlled by the amount of compressed air pressure, which should be filtered and controlled by a precision regulator. The nozzle is mounted in a large diameter, clear-plastic pipe (4-inches diameter or larger) so the output level can be observed. The aerosol generator output should connect to an injection tube with an inside diameter of at least 0.5 inches to minimize collisions with the inner wall of the tubing. Optimal operation is dependent on uniformly "wetting" the inner surfaces of the generator and transfer tubes, thus a warm up period is needed for a constant aerosol output.

\subsection{Work instructions for Setup, Measurements, and Data Reduction}

The steps taken to setup, configure, and operate the stack fans and test equipment are listed. Based on previous field measurements, the steps are ordered to achieve maximum efficiency in the testing. In addition to these steps, the test instruction illustrated in Attachment A will provide specific details and operating parameters.

\subsection{Preliminary Steps:}

6.1.1 Provide essential supplies at the sampling location. (particulate generation equipment, supply air and regulators, fittings and probe-port couplers, marking pens, data sheets, writing and probe-supporting platforms).

6.1.2 Fill in test information on dataform. DO NOT DELETE THS INM, REQURED TEXT] 
Title: Test to Determine Uniformity of a Tracer Aerosol at a Sampler Probe

6.1.3 Observe the current flow setting for the test stack and record on the data sheet.

6.1.4 Obtain barometric, temperature, and relative humidity information for the particle counter location.

6.1.5 Measure the stack centerline air velocity in the sampling plane using a velocity flow meter, and record value on data sheet.

6.1.6 Mark the sampling probe with a permanent marker so the inlet can be placed at each successive measurement point.

Note: Sampling plane traverse points. Use the grid of measurement points provided with the tests instruction and dataform. This is usually the same as used for the velocity uniformity test. A center point, is included as a common reference and for graphical purposes. The layout design divides the area of the sampling plane so that each point represents approximately an equal-sized area \{tc U3 "Potential Test Conditions\}

\subsubsection{Couple the OPCs and probes to the stack sampling ports} according to the illustration in Appendix A.

Note: The sampling equipment consists of stainless steel probes with $3 / 4$ outside diameter and thin-wall tubing with sufficient length to reach across the inside diameter of the stack while allowing for fittings. The sampling probe should have gradual $90^{\circ}$ bends, to minimize inertial impact of particles with inner walls at bends, and the open end of the tube should face downward or into the flow in the stack. The outlet end of the probe should terminate at the OPC inlet. Minimize tubing length to minimize particle losses.

The sampling probes for both OPCs should be similar and of a simple design. The elevation of the intake nozzle of the traversing unit should be approximately in the same as the sampling plane. The intake nozzle for the reference unit may be located anywhere within the stack at an elevation near that of the sampling plane; however, the two probes should not interfere with each other, either physically or by causing flow disturbances for each other. The intake nozzles may be of sub-isokinetic or of shrouded design to optimize the collection of 10 -micron particles.

The aerodynamic characteristics of the probes for both OPCs should be the same so that they have similar line-loss (penetration) values. For optimal particle collection, the probes should be of a fixed and rigid configuration. The mobile OPC with its attached probe should be mounted together on a sliding platform to move as a unit along the axis of the sampling port. 


\begin{tabular}{|l|ll|}
\hline PNNL Operating Procedure & $\begin{array}{l}\text { Rev. No. } 0 \\
\text { Org. Code: D9T99 }\end{array}$ & $\begin{array}{l}\text { Page } 6 \text { of 15 } \\
\text { Procedure No.: EMS-JAG-02 }\end{array}$ \\
\hline \multicolumn{2}{|c|}{ Title: Test to Determine Uniformity of a Tracer Aerosol at a Sampler Probe } \\
\hline
\end{tabular}

6.1.8 Turn-on the mobile and reference optical particle counters.

Note: Insure that internal air circulation fans in the OPCs are on and that the sample probes are tightly connected to and are directly above or apart from the OPC sample inlet openings. Also assure that the sliding platform supporting the mobile sampler is aligned for easy, free movement at the correct height for its stack port.

6.1.9 Program and synchronize the OPCs for:

- 60-second samples,

- 9- to 11-micron particle counting,

- the current time,

- cumulative counting mode.

\subsection{Daily Particulate Background Concentration Measurement}

6.2.1 At the beginning of each sampling day before starting the aerosol generator, obtain at least 6 consecutive background readings for both mobile and reference OPCs.

6.2.2 Record these readings on the datasheet and in the logbook designated for the tests.

6.2.3 Start and run the aerosol generator for approximately 30 minutes to stabilize its output.

\subsection{Particle Injection and Sample Collection}

The injection equipment includes an air regulator, a precision air pressure gauge, and other components described in Section 5. The 3/4-inch (OD) stainless steel injection probe with a $90^{\circ}$ bend (with an approximately 3-inch radius of turn) will inject aerosol particles in the direction of emission flow. The connections and fittings should be checked to insure that they are secure and leak free.

Note: Location of the Injection Point $\{$ tc $\cup 3$ "Potential Test Conditions\} Injection plane -- The tests are repeated using the centerpoint as the aerosol release point. 
6.3.1 Position the injection probe, according to the test instruction.

6.3.2 Start injection of the aerosol and adjust the flow rate to the input capabilities of the OPCs.

Note: Aerosol injection is not precisely controlled. At air pressure readings above about 10 psi for the specific PNNL generator used, a dense oil mist is created in the generator and is available for injection. However, if the back-pressure, caused by a high rate of airflow past the port in the stack, at the injection port is high, carrier air may be required to inject the aerosol into the base of the stack. Under these conditions the overall aerosol output will be low (less than perhaps 200 particles measured at the counter).

In contrast, if there is little back-pressure most of the generated aerosol, minus that lost from interactions with internal generator system and line walls, becomes available for injection. Here the output will be high (hundreds to thousands of particles injected per minute).

Note: The OPC draws air from the stack, via the sample probe, at a fixed rate (one cubic foot per minute). Within the OPC, the air stream with particles passes through a laser beam where the particles are counted and placed in six size categories. In the less than 0.5-micron category, several hundred thousand differential counts are typical; but in the 9- to 11-micron category, oil mists greater than about $3,000 \mathrm{cpm}$ cause a sensor over-load condition. Thus at the OPC the flow rate is fixed and a ceiling exists on the measurement of particles. Essentially, there is no adjustment of particle counting capability at the OPC and the aerosol generator becomes the controlling factor for particulate output. 
Title: Test to Determine Uniformity of a Tracer Aerosol at a Sampler Probe

\subsubsection{Record the initial:}

- Injection system dispersion pressure in psi,

- Flow rate for the mobile and reference OPC,

- Centerline flow velocity for the test stack.

6.3.4 On the datasheet label the columns of data according to the directions of the traverses.

6.3.5 Verify that the directional orientations and the numbered sample positions are consistent.

6.3.6 Position the OPC and sample probe at each measurement point in succession, and record the reading on the dataform.

Note: Each test relies on one repetition for each measurement point in each traverse direction, repeated three times. The repeats are made as three separate runs and not as three consecutive measurements at each point.

6.3.7 Perform two additional repetitions of step 6.3.6.

6.3.8 Switch the tests to the other direction and repeat steps 6.3.6 and 6.3.7.

6.3.9 Check the data sheet for completeness.

6.3.10 Record the final:

- Injection system dispersion pressure in psi

- Flow rate for the mobile and reference OPC

6.3.11 Shutoff the air pressure to the aerosol generator.

6.3.12 Continue operation of the OPCs for several minutes to purge any remaining test aerosol from the stack. 
Title: Test to Determine Uniformity of a Tracer Aerosol at a Sampler Probe

6.3.13 Measure the centerline background particulate concentrations at the mobile monitor and record the levels on the datasheet.

6.3.14 Record any climatic conditions that have changed on the datasheet.

6.3.15 Measure the final centerline stack velocity flow on the datasheet.

6.3.16 Record any deviations from the above procedure on the datasheet.

6.3.17 Repeat steps 6.3.1 - 6.3.16 for each run as indicated in the test instruction.

\subsection{Data Recording and Calculations}

Prepare the electronic data sheet on which to enter particle count readings and other information relevant to the test (see test instruction).

6.4.1 Review the raw datasheets for completeness.

6.4.2 Enter the data into the electronic datasheet.

6.4.3 Calculate the COV for the run.

Note: The EXCEL datasheet shown as Attachment $\mathrm{C}$ is setup to calculate the $\mathrm{COV}$ for each particulate concentration traverse using the average concentration data from all points in the inner two-thirds of the cross section area of the plane (including the center point).

6.4.4 Compare the observed COV for each run to the acceptance criterion.

Note: The test is acceptable if the COV is $\leq 20 \%$ for the inner two-thirds of the stack diameter, and if no point differs from the mean by more than $30 \%$. This is determined by inspection of the average concentration at each measurement point. The COV is 100 times the standard deviation divided by the mean. 
\begin{tabular}{l|ll} 
PNNL Operating Procedure & Rev. No. 0 & Page 10 of 15
\end{tabular}

Org. Code: D9T99

Procedure No.: EMS-JAG-02

Title: Test to Determine Uniformity of a Tracer Aerosol at a Sampler Probe

6.4.5 Sign and date the datasheet illustrated in Attachment $\mathrm{C}$ attesting to its validity.

Note: A separate datasheet will be provided and signed-off for each test. 


\subsection{Exhibits/Attachments}

Appendix A - Overview of Stack and Injection Setup and Particle Counters

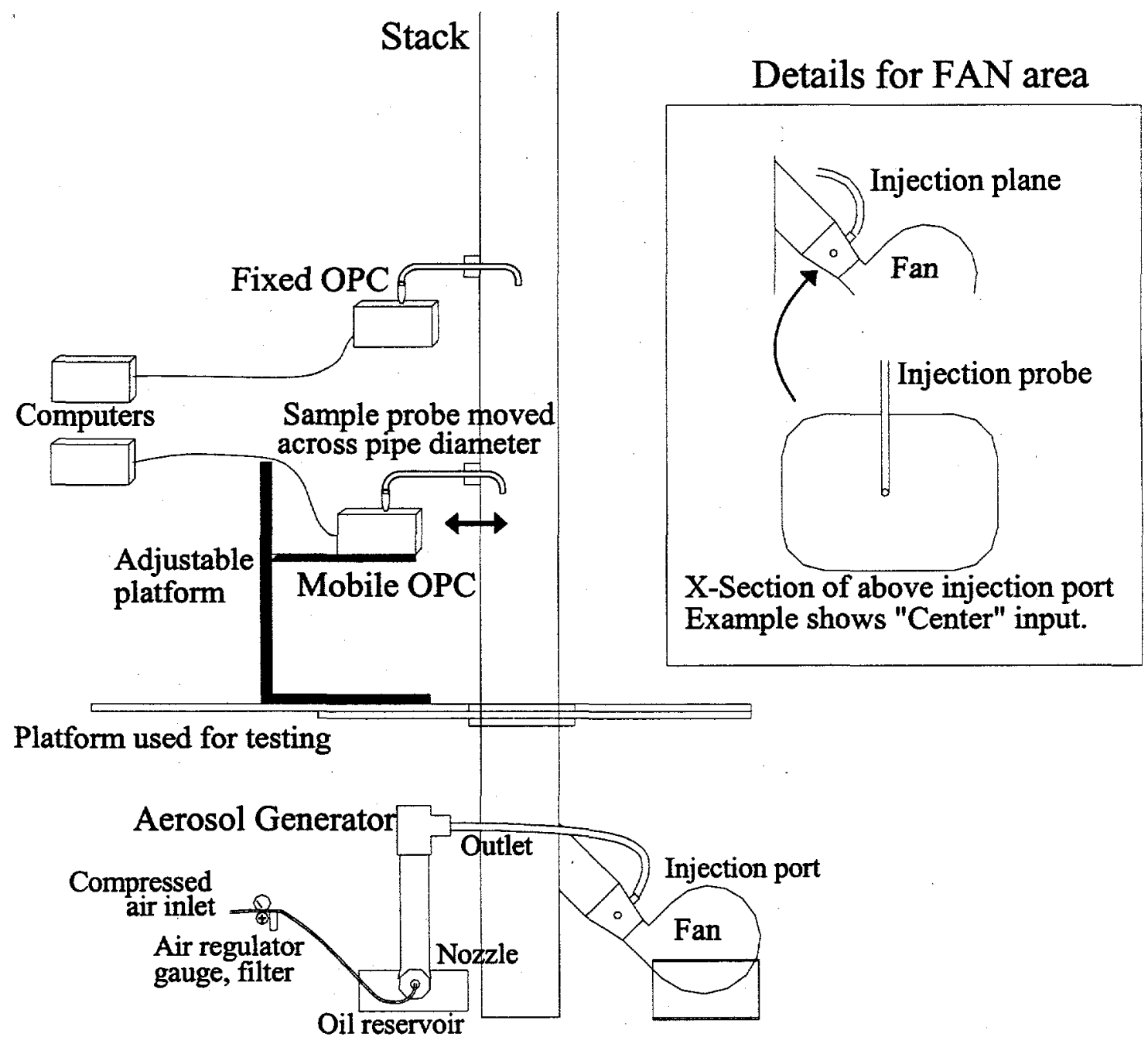

B.11 
Appendix B - Illustrative Data Collection Sheet

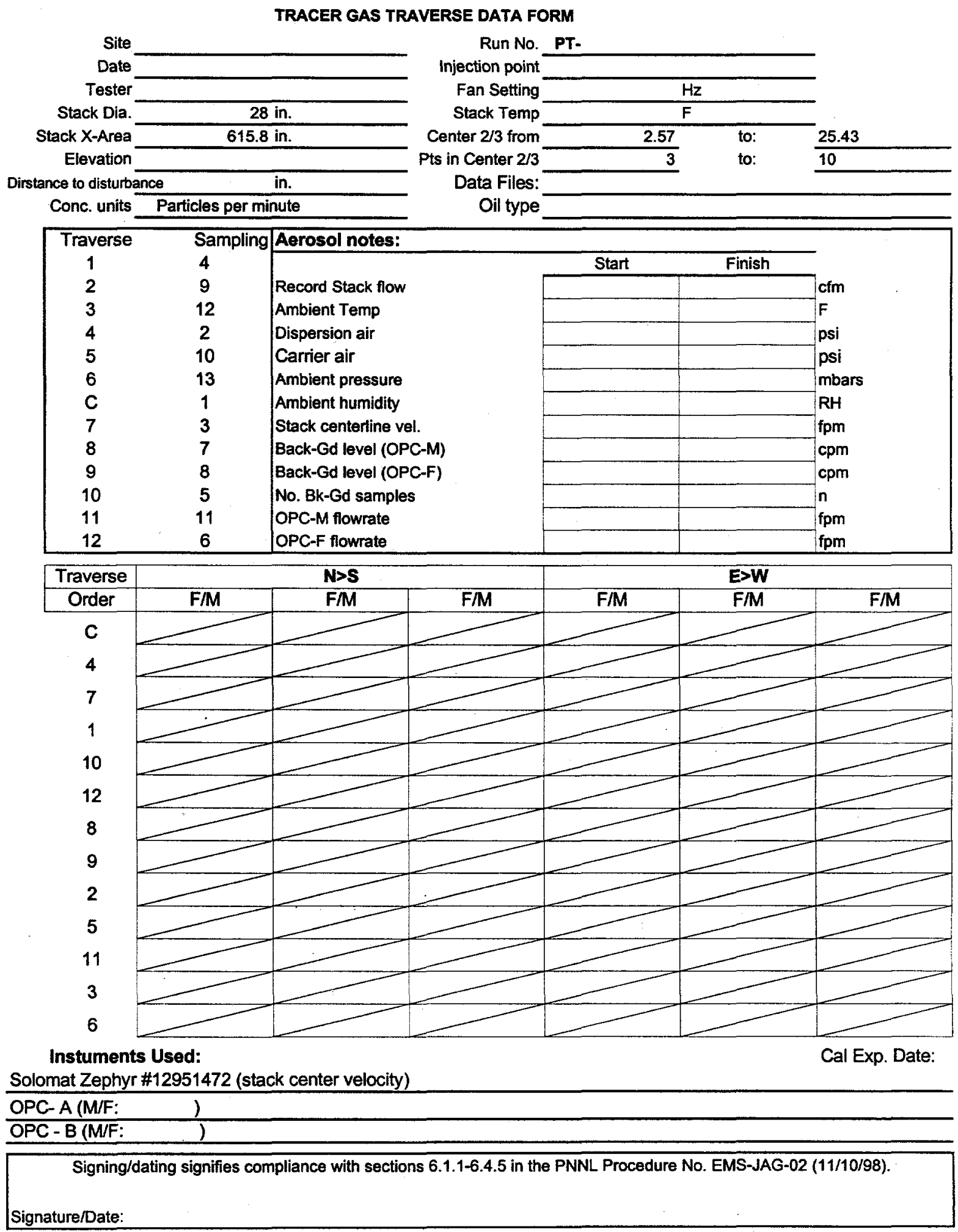

B.12 


\begin{tabular}{l|ll} 
PNNL Operating Procedure & $\begin{array}{l}\text { Rev. No. 0 } \\
\text { Org. Code: D9T99 }\end{array}$ & $\begin{array}{l}\text { Page 13 of 15 } \\
\text { Procedure No.: EMS-JAG-02 }\end{array}$
\end{tabular}

Title: Test to Determine Uniformity of a Tracer Aerosol at a Sampler Probe

Appendix C - Illustrative Data Reporting Form

PARTICULATE TRAVERSE DATA REPORT FORM

Site
Date
Tester
Stack Dia.
Stack X-Area
Elevation
Distance to disturbance
Conc. units

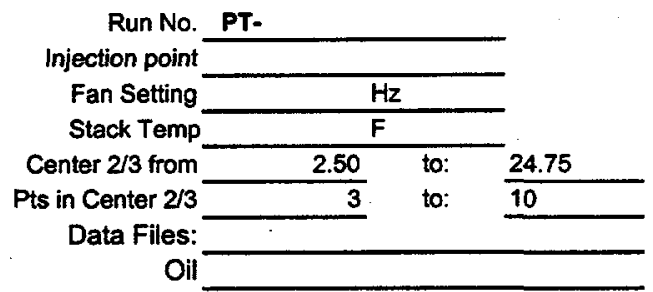

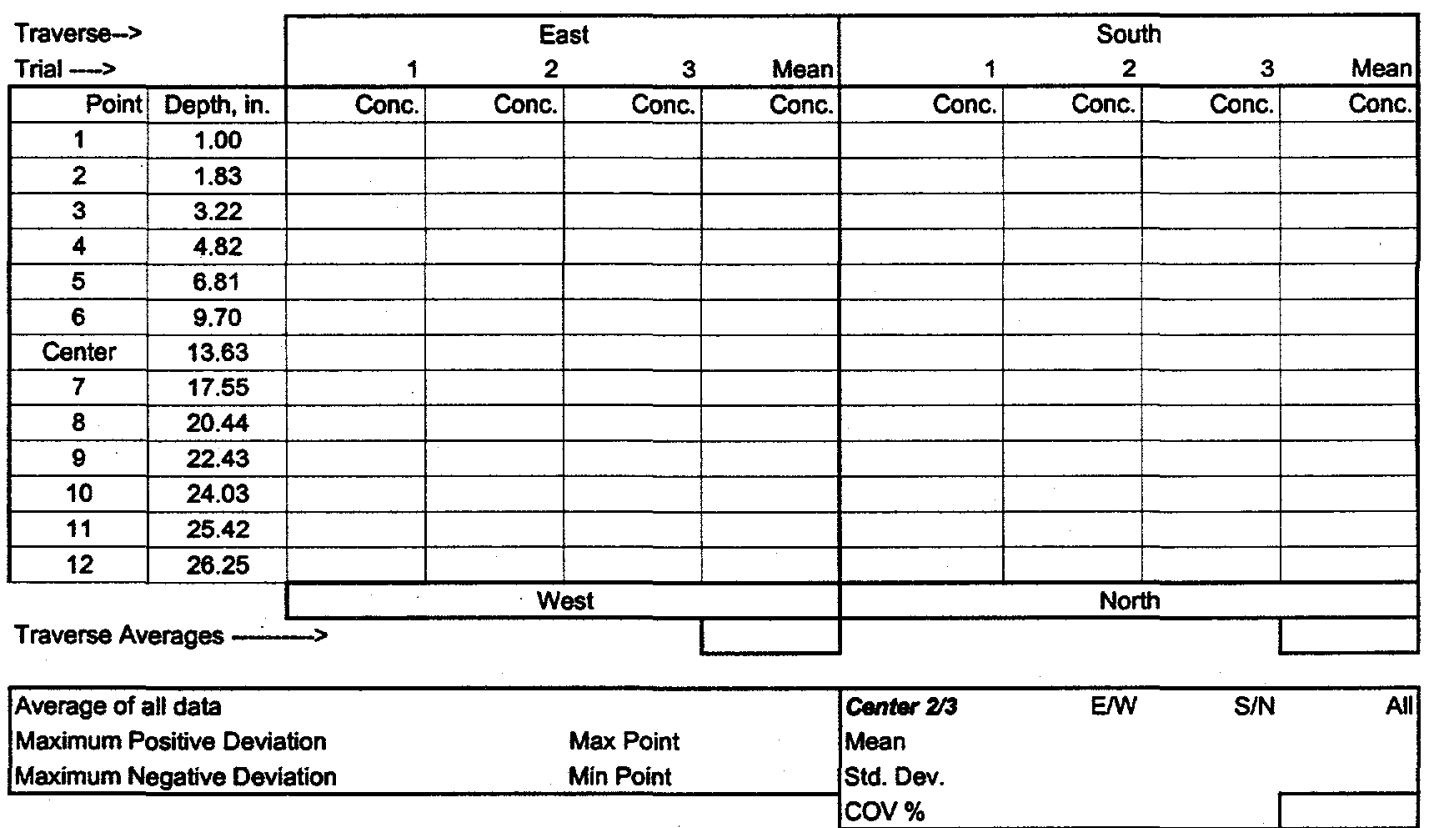

Record stack flow

Ambient temp

Dispersion air

Carrier air

Ambient pressure

Ambient humidity

Stack centerline vel.

Bk-Gd level (OPC-M)

Bk-Gd level (OPC-F)

No. Bk-Gd samples

OPC-M flowrate

OPC-F flowrate

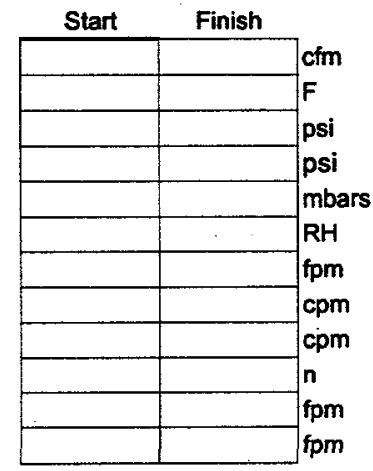

Instuments Used:

Solomat Zephyr \#12951472

B \& K Model $1302 \# 1765299$

Sierra Inc. Constant Flow Air Sampler

Signing/dating signifies compliance with Sec. 6.1.1-6.4.5 in the PNNL Procedure No. EMS-JAG-02 (11/10/98).

Signature/Date:
Gas analyzer checked

Notes:

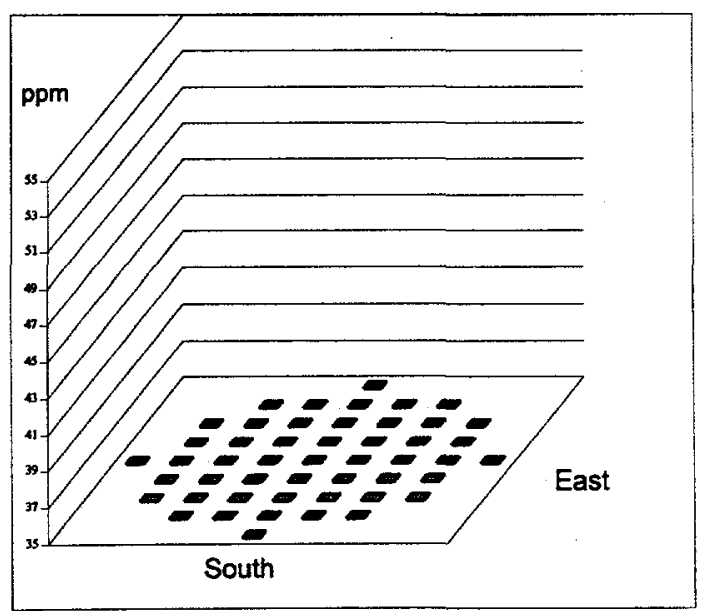

B.13 
Attachment A - Illustrative Test Instructions 


\begin{tabular}{|l|ll|}
\hline PNNL Operating Procedure & $\begin{array}{l}\text { Rev. No. } 0 \\
\text { Org. Code: D9T99 }\end{array}$ & $\begin{array}{l}\text { Page 15 of 15 } \\
\text { Procedure No.: EMS-JAG-02 }\end{array}$ \\
\hline \multicolumn{2}{|c|}{ Title: Test to Determine Uniformity of a Tracer Aerosol at a Sampler Probe } \\
\hline
\end{tabular}

\section{Test Instruction}

\begin{tabular}{|l|l|l|}
\hline $\begin{array}{l}\text { Project: Canister Storage } \\
\text { Stack Qualification, 29303 }\end{array}$ & Date: November 10, 1998 & Work Package: K97052 \\
\hline \multicolumn{3}{|c|}{ Tests: Tracer Gas Uniformity of Full-Scale Stack } \\
\hline
\end{tabular}

Staff: David Maughan, John Glissmeyer

Reference Procedures:

1. Procedure EMS-JAG-02, Rev. 0, Test to Determine Uniformity of a Particulate Aerosol at a Sampler, Nov. 10, 1998

2. Operating Manual for Met-One Optical Particle Counter (OPC), Model A2408

Equipment:

1. Canister Storage Stack and inspected work platforms

2. Vacuum pump oil, oil mist generator, air lines, regulator, precision pressure gauge

3. Oil mist injection probe, OPC sample probes, probe/stack couplers

4. OPCs with computers and links

5. Velocity measurement device

Safety Considerations:

Review and observe the applicable Duke Job Hazard Analysis for the project

Instructions:

1. Verify training on the procedure and that instrumentation is within calibration

2. Obtain Fisherbrand 19 Mechanical Pump Fluid

3. Obtain climatic information from the Hanford Weather Service, phone 373-2716 or http://etd.pnl.gov:2080/HMS/lastob.htm

4. Install equipment as directed in the procedures

5. Mark sampling probe for the measurement points shown on the data sheet

6. Verify that stack flow is about the target flowrate 9000 (2232 fpm)

7. Initially set the injection system input psi at 5 and vary to obtain particle counts at the sampling ports that are about 10 times background for 10-micron particles.

8. Set the sampler flowrate at approximately $10 \mathrm{lpm}$

9. Conduct one or more tracer mixing tests at the following sets of conditions:
Stack Flow
Injection point at duct from fan to stack

Normal

Centerline

(The injection plane should be at the fittings provided in the rectangular discharge of the fan)

10. Record data on copies of the attached the data sheet

11. Repeat the test

12. Diagram mounting fixtures and retain assembly for any subsequent re-tests

Desired Completion Date: 11/30/98

Approvals:

John Glissmeyer, Project Manager Date

Test completed by:

Date: 


\section{PARTICULATE TRAVERSE DATA REPORT FORM}

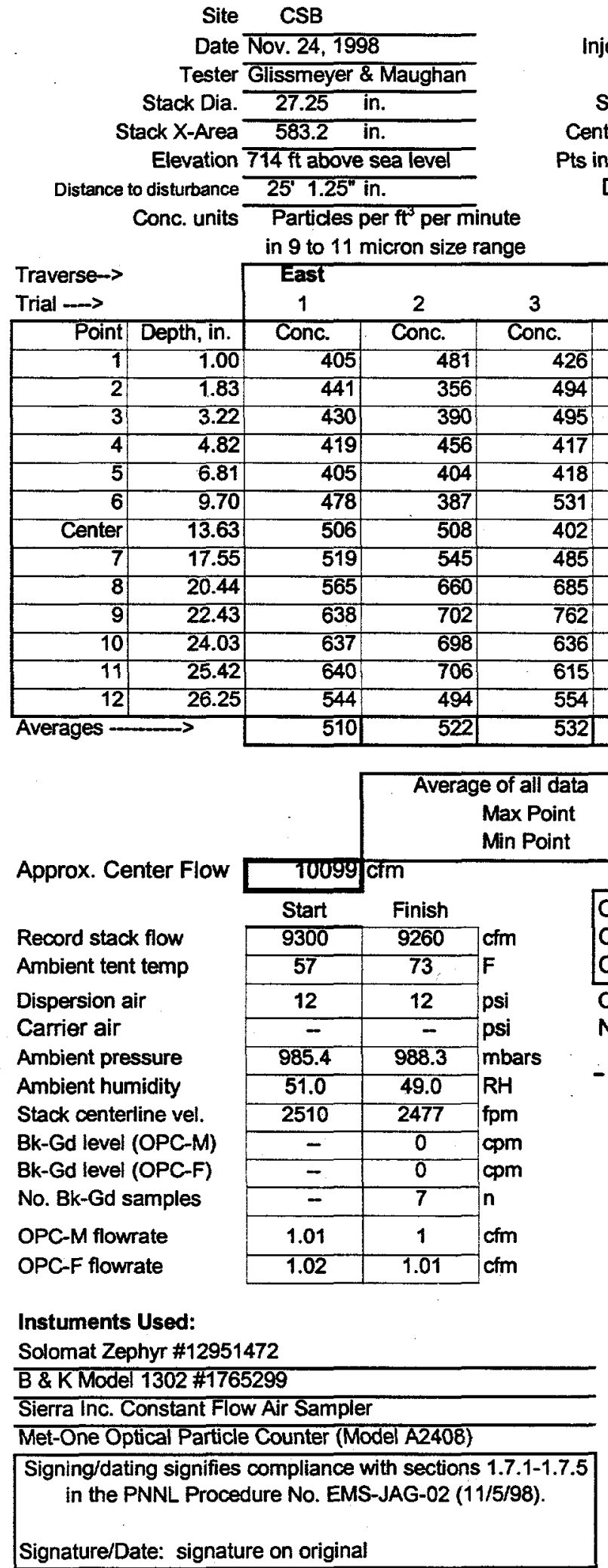

Run No. PT-Nov24_1

Injection point Center

Fan used WEST

Stack Temp

Center $2 / 3$ from $2.50 \quad$ to: $\quad 24: 75$

ts in Center 2/3 $\frac{3}{\text { none }}$ to: $\frac{10}{\text { Data Files: }}$

Oil Fisherbrand 19 Vacuum Pump Oil

Oll Fisherbrand 19 Vacuum Pump Oil

\begin{tabular}{|c|c|c|c|c|}
\hline Mean & $\begin{array}{c}\text { South } \\
1\end{array}$ & 2 & 3 & Mean \\
\hline Conc. & Conc. & Conc. & Conc. & Conc. \\
\hline 437.3 & 494 & 367 & 470 & 443.7 \\
\hline 430.3 & 438 & 483 & 446 & 455.7 \\
\hline 438.3 & 390 & 501 & 459 & 450.0 \\
\hline 430.7 & 428 & 446 & 456 & 443.3 \\
\hline 409.0 & 408 & 502 & 435 & 448.3 \\
\hline 465.3 & 418 & 442 & 473 & 444.3 \\
\hline 472.0 & 424 & 417 & 459 & 433.3 \\
\hline 516.3 & 487 & 465 & 425 & 459.0 \\
\hline 636.7 & 507 & 592 & 505 & 534.7 \\
\hline 700.7 & 458 & 555 & 473 & 495.3 \\
\hline 657.0 & 513 & 571 & 512 & 532.0 \\
\hline 653.7 & 468 & 602 & 584 & 551.3 \\
\hline 530.7 & 568 & 537 & 486 & 530.3 \\
\hline 521.38 & 462 & 498 & 476 & 478.56 \\
\hline
\end{tabular}

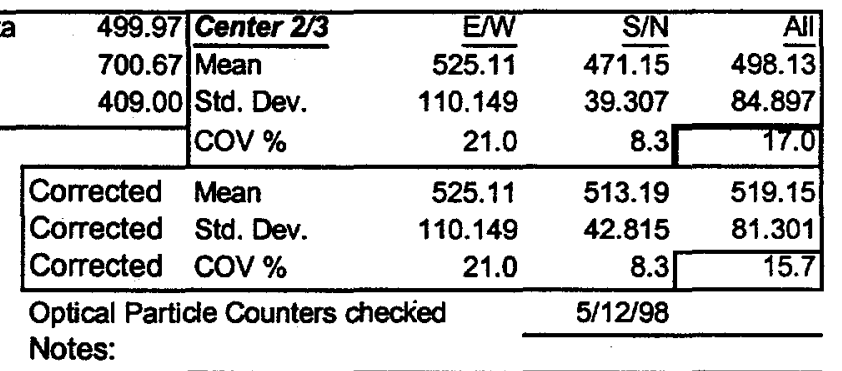

Notes:

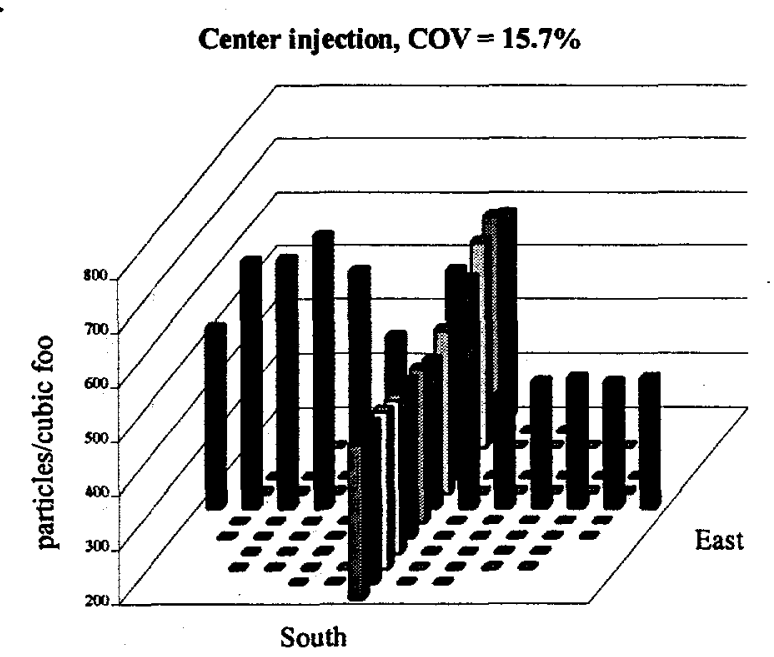

B.16 


\section{PARTICULATE TRAVERSE DATA REPORT FORM}

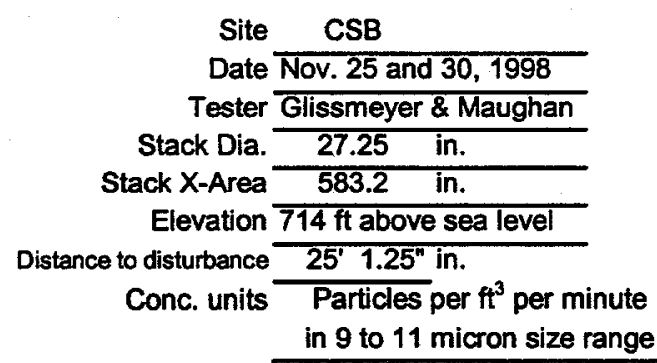

\begin{tabular}{|c|c|c|c|}
\hline Run No. & PT-Nov25_1 & & \\
\hline Injection point & Center & & \\
\hline Fan used & WEST & & \\
\hline Stack Temp & 63 & & \\
\hline Center $2 / 3$ from & 2.50 & to: & 24.75 \\
\hline Pts in Center $2 / 3$ & 3 & to: & 10 \\
\hline Data Files: & none & & \\
\hline
\end{tabular}

Trial $\longrightarrow$

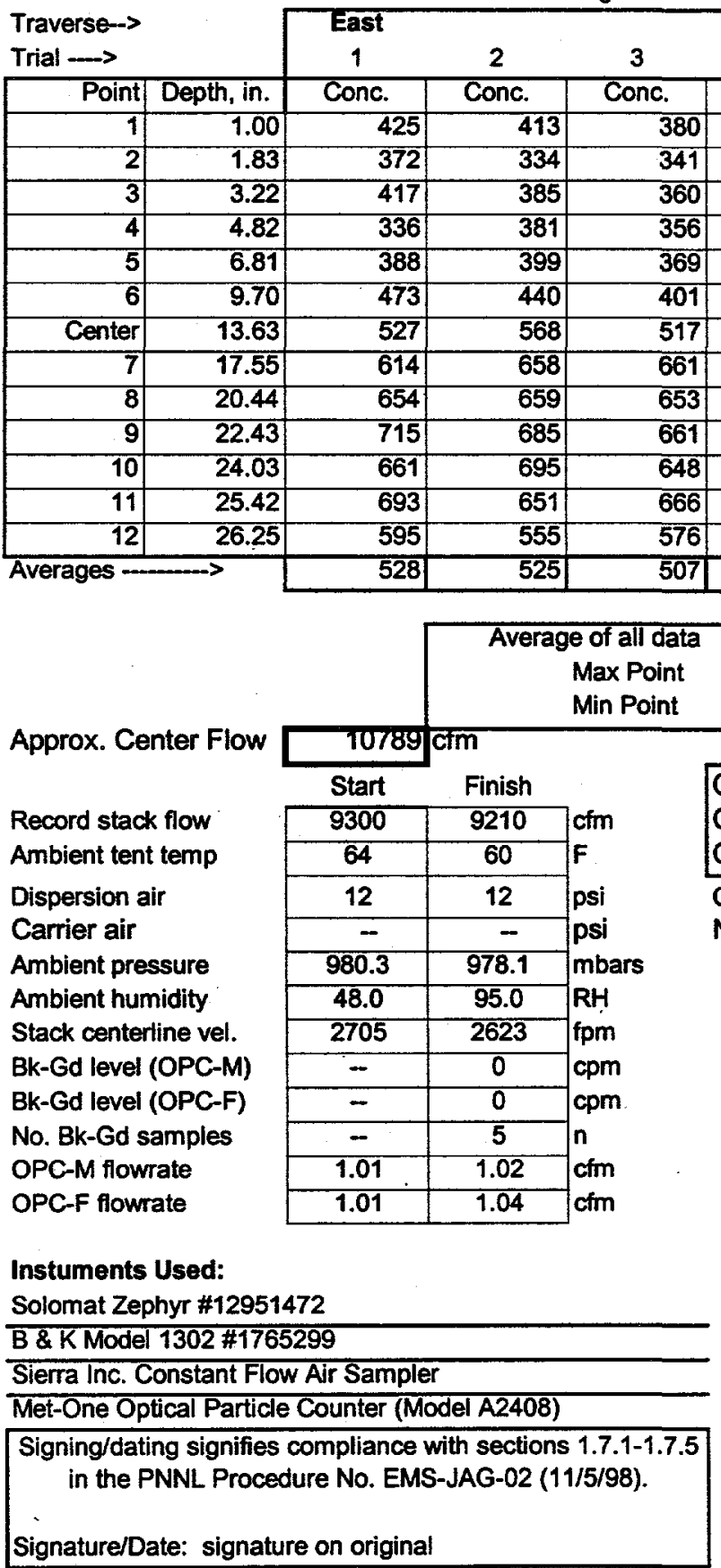

Oil Fisherbrand 19 Vacuum Pump oा 


\section{Reference}

40 CFR 61, Subpart H, U.S. Environmental Protection Agency, "National Emission Standards for Emissions of Radionuclides Other than Radon from Department of Energy Facilities." Code of Federal Regulations. 
Appendix C

Particle Penetration Calculation 


\section{Appendix C: Particle Penetration Calculation}

\section{Estimated Penetration for Canister Storage \\ Building Stack Air Sampling System \\ Results of DEPOSITION 4.0 Analysis}

For a 1.5-Inch-Diameter Tube, $9300 \mathrm{cfm}$ Stack Flow

Deposition 4.0. Thu Mar 11 14:20:341999

Exit Exit Total

Stokes \# Reynolds \# Penetration

$0.0075 \quad 2045 \quad 90.7 \%$

Element \# Element Penetration Stokes \# Reynolds \# Notes
1. Probe

$98.4 \% \quad 0.0075 \quad 2045$
2. Bend
$96.7 \% \quad 0.0075$
2045 Bend angle: 90.000 degrees.
3. Tube
$98.6 \% \quad 0.0075$
2045 Length: $0.120 \mathrm{~m}$, At 0.000 degrees from horizontal.
4. Bend
$96.7 \% \quad 0.0075$
2045 Bend angle: 90.000 degrees.
5. Tube
$100.0 \% \quad 0.0075$
2045 Length: $6.930 \mathrm{~m}$, At 90.000 degrees from horizontal.

Ambient temperature (deg.C) : $\quad 27.0$

Ambient pressure $(\mathrm{mm} \mathrm{Hg}) \quad: \quad 745.0$

Flow rate $(\mathrm{L} / \mathrm{min}) \quad: \quad 56.6$

Free strem velocity $(\mathrm{m} / \mathrm{s}): \quad 11.7$

Particle diameter $(\mu \mathrm{m}) \quad: \quad 10.0$

NOTES

$<$ Calculations were made with the best possible >

$\ll$ extrapolations of the model(s). $\quad \gg$ 


\section{Distribution}

No. of

Copies

OFFSITE

2 DOE/Office of Scientific and Technical Information

\section{ONSITE}

12 Duke Engineering and Services

Hanford, Inc.

R.G. Pedigo (12) S1-53

11 Pacific Northwest National Laboratory

J. A. Glissmeyer (5) K6-80

J.G. Droppo, Jr. (1) K6-80

Information Release Office (5) K1-06

Distr.1 